\title{
Genome, Transcriptome, and Functional Analyses of Penicillium expansum Provide New Insights Into Secondary Metabolism and Pathogenicity
}

\author{
Ana-Rosa Ballester, ${ }^{1}$ Marina Marcet-Houben, ${ }^{2,3}$ Elena Levin, ${ }^{4}$ Noa Sela, ${ }^{4}$ Cristina Selma-Lázaro, ${ }^{1}$ \\ Lourdes Carmona, ${ }^{1}$ Michael Wisniewski, ${ }^{5}$ Samir Droby, ${ }^{4}$ Luis González-Candelas, ${ }^{1}$ and Toni Gabaldón ${ }^{2,3,6}$ \\ ${ }^{1}$ Instituto de Agroquímica y Tecnología de Alimentos (IATA-CSIC), Avda. Agustin Escardino 7, Paterna, Valencia 46980, \\ Spain; ${ }^{2}$ Bioinformatics and Genomics Programme. Centre for Genomic Regulation (CRG), Dr. Aiguader, 88.08003 Barcelona, \\ Spain; ${ }^{3}$ Universitat Pompeu Fabra (UPF), 08003 Barcelona, Spain; ${ }^{4}$ Department of Postharvest Science, ARO, The Volcani \\ Center, P.O.Box 6, Bet Dagan 50250, Israel; ${ }^{5}$ Appalachian Fruit Research Station, USDA-ARS, 2217 Wiltshire Road, \\ Kearneysville, WV 25430, U.S.A.; ${ }^{\circ}$ Institució Catalana de Recerca i Estudis Avançats (ICREA), Pg. Lluís Companys 23, \\ 08010 Barcelona, Spain
}

Submitted 12 September 2014. Accepted 15 October 2014.

The relationship between secondary metabolism and infection in pathogenic fungi has remained largely elusive. The genus Penicillium comprises a group of plant pathogens with varying host specificities and with the ability to produce a wide array of secondary metabolites. The genomes of three Penicillium expansum strains, the main postharvest pathogen of pome fruit, and one Pencillium italicum strain, a postharvest pathogen of citrus fruit, were sequenced and compared with 24 other fungal species. A genomic analysis of gene clusters responsible for the production of secondary metabolites was performed. Putative virulence factors in $\boldsymbol{P}$. expansum were identified by means of a transcriptomic analysis of apple fruits during the course of infection. Despite a major genome contraction, $P$. expansum is the Penicillium species with the largest potential for the production of secondary metabolites. Results using knockout mutants clearly demonstrated that neither patulin nor citrinin are required by $P$. expansum to successfully infect apples.

The genus Penicillium - from the Latin "painter's brush," which refers to the characteristic morphology of its conidial

Ana-Rosa Ballester and Marina Marcet-Houben contributed equally. Luis González-Candelas and Toni Gabaldón share senior authorship

Current address for Lourdes Carmona: Food Science and Tecnhonolgy Department. Universidad de Santiago de Chile. Obispo Umaña 050, Estación Central. Chile.

Nucleotide sequence data from the Whole Genome Shotgun projects have been deposited in the DDBJ/EMBL/GenBank database under the accession numbers JQFX00000000, JQFY00000000, JQFZ00000000, and JQGA00000000 for Penicillium expansum strains CMP-1, d1, and MD-8 and $P$. italicum PHI-1, respectively. The versions described in this paper are JQFX01000000, JQFY01000000, JQFZ01000000, and JQGA01000000. The raw RNA-Seq data files are deposited in the National Center of Biotechnology Information (NCBI) database under SRA accession number SRP043407.

Corresponding authors: Toni Gabaldon; E-mail: tgabaldon@crg.es and Luis González-Candelas; E-mail: lgonzalez@iata.csic.es

* The $\boldsymbol{e}$-Xtra logo stands for "electronic extra" and indicates that eleven supplementary figures and nine supplementary tables are published online.

(C) 2015 The American Phytopathological Society chains - comprises a group of anamorphic fungi in the division Ascomycota. The genus Penicillium is large, with 150 recognized species, of which 50 or more are of common occurrence (Pitt and Hocking 2009). Penicillia are generally soil fungi and are ubiquitous in warm and moderate climates. Some species are of economic importance to the food industry because they are used in the production of cheese and meat products or because they are postharvest pathogens that cause spoilage. Classification within this genus has undergone revision on the basis of several newly considered criteria, one of which is the ability to produce specific secondary metabolites (Frisvad and Filtenborg 1983; Frisvad and Samson 2004; Paterson et al. 2004). The production of secondary metabolites is a characteristic of Penicillium species. In general, these compounds are not essential for the normal growth, development, and reproduction of the organism but may confer important ecological advantages, such as eliminating competing microbial species. Secondary metabolites can also be the source of important bioactive compounds. The use of penicillin, derived from $P$. chrysogenum, as the first broad-spectrum antibiotic constitutes a prime example.

Penicillium expansum, the type species of the genus, is the causal agent of blue mold, which is considered one of the most important postharvest rots of pome fruit (Cappellini et al. 1987; Jurick et al. 2011). Postharvest decay of apple can result in financial losses exceeding $\$ 4.5$ million per year in the United States alone (Rosenberger 1997). P. expansum is also of great concern to fruit processing industries (e.g., juicing, baby food, ready-to-eat salads) due to its ability to produce patulin, a highly toxic mycotoxin that can contaminate infected fruits and their derived products (McCallum et al. 2002; Wouters and Speijers 1996). Despite the economic impact of $P$. expansum, knowledge about the molecular basis of its interactions with the plant host as well as with other microorganisms is insufficient. In particular, the relationship between secondary metabolite production and virulence remains poorly understood.

$P$. expansum is reported to produce a wide array of secondary metabolites (Andersen et al. 2004). This includes, among other compounds, citrinin, ochratoxin A, patulin, penitrem A, and rubratoxin B (Leistner and Pitt 1977). The combination of metabolites produced by $P$. expansum is indicative for this species and is considered to be independent of the geographic region it inhabits and the substrate it grows on (Andersen et al. 
2004). Patulin is the most common mycotoxin produced by $P$. expansum. It is a relatively small molecule that may also be produced by other Penicillium species as well as by various Aspergillus species and fungi of other genera. Exposure of humans to patulin via consumption of contaminated fruit and fruit products may result in severe toxicosis, including mutagenic, teratogenic, hepatotoxic, nephrotoxic, neurotoxic, and genotoxic effects (Hopkins 1993). At high doses, patulin exhibits immunosuppressive properties (Sharma 1993). Sommer and associates (1974) reported that different $P$. expansum strains produced varying levels of patulin during apple infection, ranging from 2 to $100 \mu \mathrm{g} / \mathrm{g}$, and that levels were not related to either pathogenicity or virulence of the different strains. The same lack of correlation between virulence and in vivo patulin production was reported by Martins and associates (2002). These observations led to the suggestion that patulin probably does not play a role in $P$. expansum pathogenicity. More recently, however, Sanzani and associates (2012) reported a direct relationship between patulin production and blue mold incidence and severity on apples. In that study, disruption of the gene coding for 6-methyl-salicylic acid synthase, an enzyme involved in the first committed step of patulin biosynthesis, resulted in mutants producing 33 to $41 \%$ less patulin than the corresponding wild-type strain. Such mutants exhibited reduced pathogenicity and virulence (40 to $50 \%$ reduction) on artificially inoculated apples. The involvement of patulin in pathogenicity was further supported by Barad and associates (2014), when they found RNAi-mediated knock down of an $I D H$ gene coding for one of the later enzymes in the patulin biosynthesis pathway resulted in a $87.5 \%$ decrease in patulin production in solid culture medium and a 12 to $28 \%$ reduction in the virulence of $P$. expansum on apple. Furthermore, conditions enhancing a decrease in D-gluconic acid (GLA) accumulation in glucose oxidase GOX2-RNAi and PACC-RNAi mutants affected patulin accumulation, suggested that GLA production, not low $\mathrm{pH}$, was the driving force for increased patulin accumulation. Barad and associates (2014) concluded that GLA and patulin are both pathogenicity factors in $P$. expansum and that the levels of these compounds are modulated by the $P A C C$ transcription factor that is expressed in the fungus during fruit colonization. Thus, the existing literature, based on natural strains and artificial mutants with varying degrees of patulin production, is inconsistent regarding the possible involvement of this toxin in the pathogenicity and virulence of $P$. expansum.

In order to provide information on the genomic basis of the production of secondary metabolites in $P$. expansum compared with other penicillia and to investigate the possible role of secondary metabolites, particularly of patulin, in pathogenicity, three strains of $P$. expansum and one strain from the closelyrelated $P$. italicum were sequenced and compared with six other sequenced Penicillium species: penicillin-producing $P$. chry- sogenum (van den Berg et al. 2008); the main postharvest pathogen of citrus, $P$. digitatum (Marcet-Houben et al. 2012); the lignocellulose-degrading $P$. oxalicum ( $P$. decumbens) (Liu et al. 2013); and two cheese-related Penicillium species, $P$. roqueforti and $P$. camemberti (Cheeseman et al. 2014). A recently reported genome assigned to the endophytic fungal species $P$. aurantiogriseum (Yang et al. 2014) was also included, though our results indicate that the strain of this species used for genome sequencing was misidentified and should be considered as another P. expansum strain. Lastly, the production of different metabolites were measured in mutants constructed to disrupt the patulin and citrinin pathways, and RNA-Seq transcriptome analysis of $P$. expansum was performed during the course of infection of apple fruits. Results indicate the presence of a large number of secondary metabolism gene clusters in P. expansum that are absent in other sequenced Penicillium genomes. Interestingly, some of the clusters seem to be implicated in horizontal gene transfers (HGT) with other distant microbes. A $P$. expansum strain unable to produce patulin was identified and the possible causative mutations responsible for this phenotype are proposed. Based on the data obtained from the knockout mutants in which the patulin and citrinin pathways were disrupted, results support the premise that neither of these two mycotoxins are directly involved in the mechanism of pathogenicity of $P$. expansum on apples. Remarkably 20 predicted metabolic clusters with increased expression during apple infection were identified in the RNA-Seq data, nine of which were specifically expressed during infection. This suggests the possible involvement of other secondary metabolites as well as additional putative pathogenicity factors in the pathogenesis of $P$. expansum.

\section{RESULTS AND DISCUSSION}

\section{Comparative genomics.}

Genome sequences of three $P$. expansum strains isolated in Israel (Pd1/PEXP), Spain (CMP1/PEX1), and the United States (MD-8/PEX2), and one $P$. italicum strain isolated in Spain (PHI/PITC) were sequenced using the Illumina Hiseq 2000 pair-end approach (discussed below). The final assemblies resulted in 260 to 1,700 contigs and had an average coverage ranging from 73 to $605 \times$ (Table 1). All sequenced strains were of the same mating type (MAT-1). Regarding the number of single nucleotide ploymorphisms (SNP), the Spanish (PEX1) and Israeli (PEXP) strains are more similar to each other (1.38 SNP per $\mathrm{kb}$ ) than to the strain isolated in the United States (PEX2, 1.86 SNP per kb with respect to PEXP). PEXP was chosen as the reference genome for $P$. expansum based on the statistics of its assembly, as it had fewer contigs and higher coverage and N50 than the others (Table 1). Roughly 10,000 to 11,000 protein-coding genes were annotated in the newly assembled genomes, a number significantly larger than the

Table 1. Assembly statistics for the genomes obtained for this study

\begin{tabular}{lllll}
\hline Variable & Penicillium expansum & \multicolumn{1}{c}{ P. expansum } & P. expansum & P. italicum \\
\hline Code & PEXP & PEX1 & PEX2 & PITC \\
Source & Decayed apple, Israel & Decayed apple, Spain & Decayed apple, United States & Decayed mandarin, Spain \\
Genome size & $32,065,046$ & $31,087,040$ & $32,357,513$ & $32,076,980$ \\
Number of contigs & 269 & 1,723 & 377 & 1,633 \\
Coverage & $605 \times$ & $73 \times$ & $473 \times$ & $421 \times$ \\
Number of contigs $>100 \mathrm{~kb}$ & 89 & 9 & 100 & 104 \\
Number of scaffolds & 249 & 1723 & 345 & 860 \\
Number of scaffolds $>100 \mathrm{~kb}$ & 80 & 9 & 89 & 89 \\
Number N (scaffolds/contigs) & $911 / 319$ & $0 / 0$ & $1,393 / 334$ & $1,712,083 / 1287$ \\
N50 (scaffolds) & 42,2053 & 31,189 & 376,691 & 267,389 \\
GC $(\%)$ & 47.6 & 48.2 & 47.6 & 47.1 \\
Number of protein-coding genes & 11,048 & 10,683 & 11,070 & 10,001 \\
\hline
\end{tabular}


A

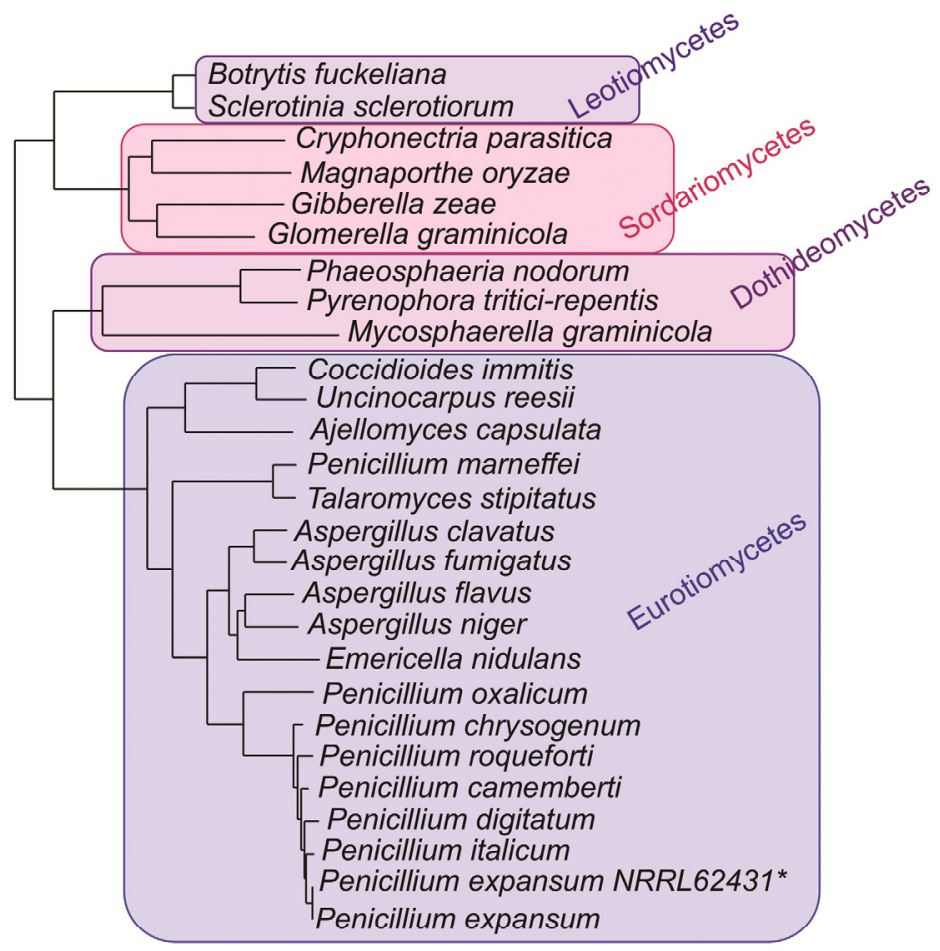

B
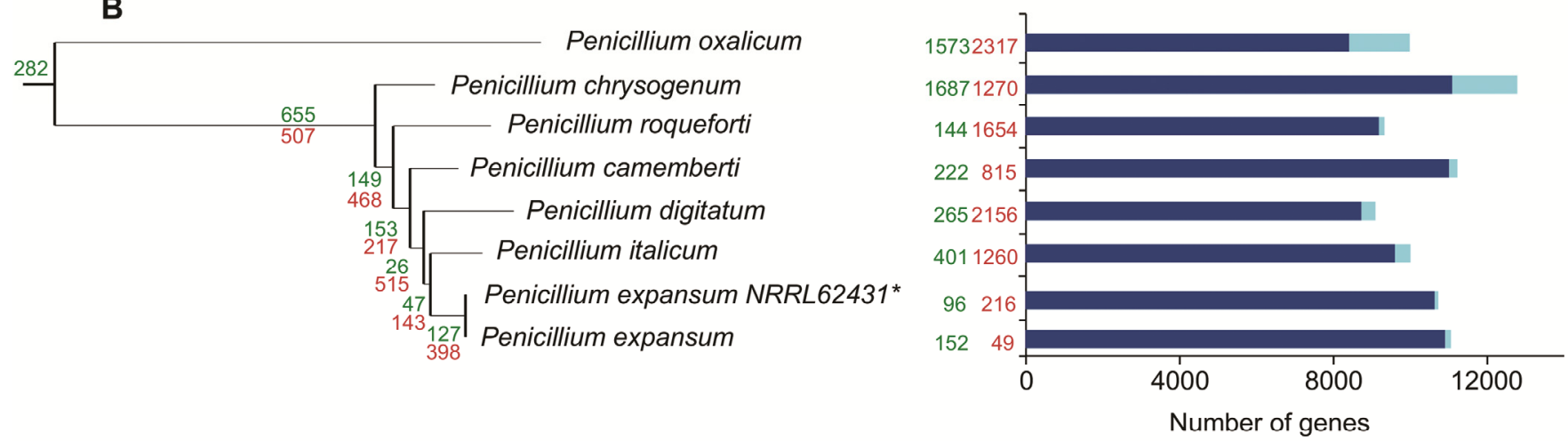

C

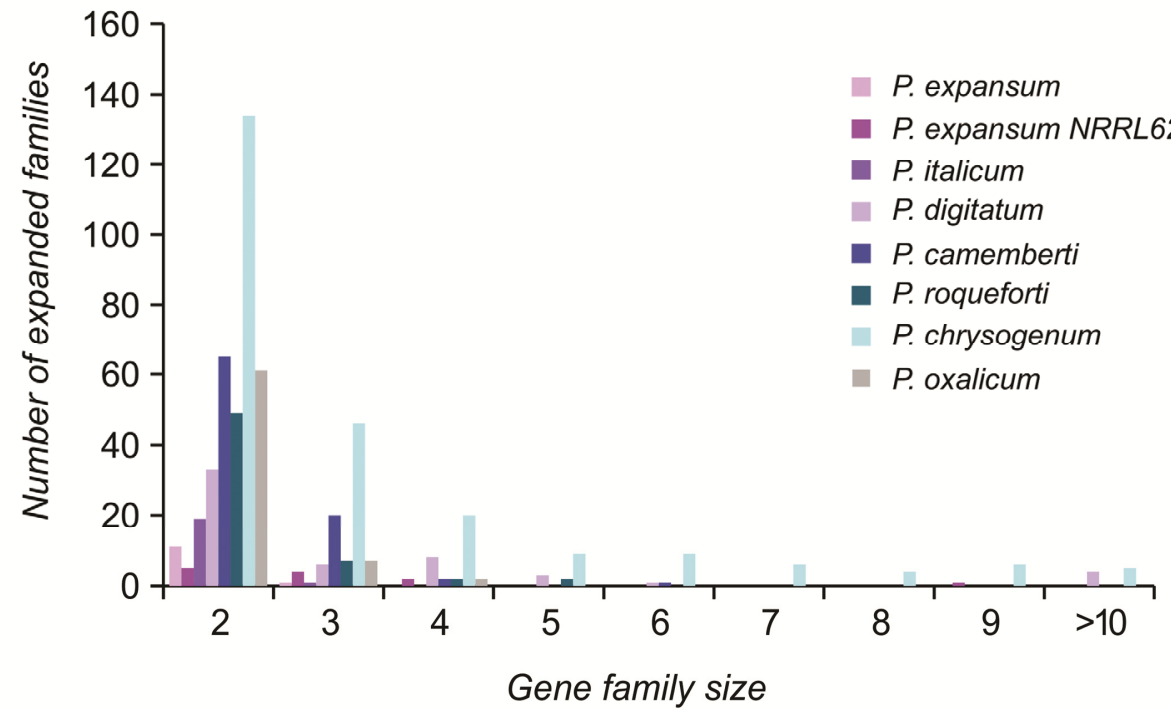

Fig. 1. Comparative genomics of Penicillium species. A, Maximum likelihood species tree derived through gene concatenation of 524 single-copy genes that are present in all species considered. All bootstrap values are maximal (100). B, Detail of the phylogeny containing the considered penicillia. Numbers on branches and next to the species name indicate average number of gene gain (green) and gene loss (red), as inferred from collections of gene trees (phylomes). Bars next to species names represent the number of genes encoded in the genome. The light blue sector indicates the number of unique genes in this species in relation to the species used in the phylome. $\mathbf{C}$, Size distribution of gene families resulting from species-specific duplications (i.e., number of resulting in-paralogs) for each of the eight Penicillium species examined. 
9,133 proteins predicted in the closely related species $P$. digitatum (Marcet-Houben et al. 2012).

The newly sequenced genomes were compared with the genome sequences of 25 other Pezizomycotina species, including the closely related $P$. digitatum, $P$. chrysogenum, $P$. aurantiogriseum, $P$. roqueforti, $P$. camemberti, and $P$. oxalicum, 10 other eurotiomycetes, three dothideomycetes, two leotiomycetes, and four sordariomycetes (Supplementary Table S1). The evolutionary relationships of these species were reconstructed by analyzing 524 genes found to be widespread and present as a single copy. Results support a clade formed by the seven penicillia, $P$. chrysogenum, $P$. roqueforti, $P$. camemberti, $P$. digitatum, $P$. italicum, $P$. aurantiogriseum, and $P$. expansum, with the latter two species being extremely closely related (Fig. 1A). Indeed $P$. aurantiogriseum and $P$. expansum PEXP shared a $99.76 \%$ average protein identity, which was very similar to the $99.79 \%$ protein identity shared between the PEXP and PEX2 strains of $P$. expansum. This result is in sharp contrast to the existing taxonomic classification, which places these latter two Penicillium species in different sections and series within the subgenus Penicillium (Frisvad and Samson 2004). Therefore, it was suspected that the current genome sequence purported to be $P$. aurantiogriseum (Yang et al. 2014) may represent a case of misidentification. This premise was tested by comparing all strains with existing sequences from phylogenetic markers present in the database (e.g., calmoludin, RNA polymerase). The analysis clearly showed that the genome sequence assigned to $P$. aurantiogriseum clusters with the sequenced $P$. expansum strains and far away from other typed $P$. aurantiogriseum strains (Supplementary Fig. S1). Thus, the genome assigned to $P$. aurantiogriseum NRRL 62431 does not appear to belong to the purported species and should, instead, be considered a strain of $P$. expansum. Taking into account this evidence, we propose renaming this strain $P$. expansum NRRL 62431. Comparing the consistency of newly sequenced genomes with existing sequences from phylogenetic markers from the same species should be a general practice that would enable early detection of such errors.

Detailed examination of the evolutionary relationships of the seven Penicillium species using 2,147 genes confirmed the previously identified relationships, producing a clade of six related species with $P$. oxalicum forming a relatively distant outgroup (Fig. 1B). Remarkably, genome size in these tightly related species exhibit large differences, with proteomes ranging from 9,133 proteins in $P$. digitatum to 12,791 in $P$. chrysogenum (Fig. 1B). To gain insight into the source of this variation, the dynamics of gene family expansions and contractions of these seven penicillia, using $P$. oxalycum as an outgroup, were analyzed. This was accomplished by reconstructing complete sets of the evolutionary histories of all the genes encoded in each of their genomes (i.e., the phylomes). The resulting gene trees were deposited in PhylomeDB (Huerta-Cepas et al. 2014). The phylomes were scanned in order to establish orthology and paralogy relationships (Gabaldón 2008) and to predict and date duplication events (Huerta Cepas and Gabaldón 2011).

The observed differences in genome size could have evolved by a combination of differential gene gain and loss rates within families present across the compared species as well as by a variable number of species-specific genes (Fig. 1B). More specifically, $P$. digitatum appears to have experienced a recent contraction in its gene repertoire, with a net decrease of 1,891 proteincoding genes that were specifically lost in that lineage (MarcetHouben et al. 2012). At the other extreme, $P$. chrysogenum has the largest genome with a significant fraction of its genome represented by species-specific genes (13\% of its genome). Most of the species-specific genes in $P$. chrysogenum are part of lineagespecific gene family expansions, which tend to be larger relative to expanded families in other Penicillium species (Fig. 1C). Thus, the genome in Penicillium species appears to be very dynamic, with lineage-specific variations in genome size representing up to $20 \%$ of the genome. Interestingly, a relationship between genome or proteome size and host range appears to be present among the three species of Penicillium that are fruit pathogens. $P$. digitatum, which shows the most restricted host range, has the smallest proteome, whereas $P$. expansum, which is able to infect many other hosts in addition to pome fruit, has the largest proteome. P. italicum falls between the other two species both in genome size and host range.

\section{A rich repertoire of secondary metabolite gene clusters in $P$. expansum including an ancestrally acquired patulin cluster.}

The secondary metabolism of the Penicillium clade was analyzed by searching their genomes for a set of 98 described metabolic clusters and for the presence of signature proteins such as nonribosomal peptide synthetases (NRPS) and polyketide synthases (PKS) (discussed below) (Supplementary Table S2). Twenty-two (22\%) of the 98 described clusters were found, at least in part, in one or more of the Penicillium species (Fig 2A; Supplementary Table S3). This number is likely to represent a minimal fraction of the true number of secondary metabolism gene clusters, considering that, in any species, the number of known clusters is just a small fraction of the number of detected signature proteins (Fig. 2A). Most of the detected clusters are discontinuously distributed within the penicillia, with only one cluster, the conidial pigment cluster, present in all the species investigated except $P$. oxalicum.

$P$. expansum has the largest number of identified secondary metabolite gene clusters among the sequenced Penicillium species and is the species with the largest number of signature proteins (65 to 67) and corresponding clusters as predicted by SMURF (Supplementary Table S4) (Khaldi et al. 2010). In comparison, other Penicillium species contain between 32 and 54 signature proteins. Among the clusters found in the $P$. expansum genome, a patulin gene cluster was identified that has a configuration similar to the patulin cluster found in Aspergillus clavatus (Fig. 2B). Notably, several Penicillium species unable to produce patulin contain several of the genes that are part of the patulin cluster and are located in close proximity to each other and in the same order as found in Penicillium species that do produce patulin. In some species, remnants of some of the missing genes can be detected by homology searches (Fig. 2B). This suggests that the presence of the patulin cluster is an ancestral trait in penicillia and likely predates the divergence of $P$. roqueforti. Since that divergence, most of the current sequenced lineages, with the notable exception of $P$. expansum, have lost the ability to synthesize patulin due to the degeneration of the cluster. These results explain the observation that other penicillia within this clade, not necessarily closely-related to $P$. expansum, can synthesize patulin (Frisvad and Samson 2004). A citrinin gene cluster was also identified with a size intermediate to the clusters identified in Monascus aurantiacus and M. purpureus (Supplementary Fig. S2). The genes in the predicted cluster of $M$. aurantiacus that are not in the cluster in $P$. expansum have only distant homologs that are located elsewhere in the genome, suggesting that these genes may not be actually involved in the synthesis of citrinin. Curiously, the gene cluster responsible for the synthesis of a cytochalasan compound, which has been described in $P$. expansum (Schümann and Hertweck 2007), was not found in the strains sequenced in the present study, but a very similar cluster was found to be partially present in $P$. decumbens and in $P$. digitatum. None of the Penicillium species, with the exception of $P$. chrysogenum, are predicted to be able to synthesize penicillin. 

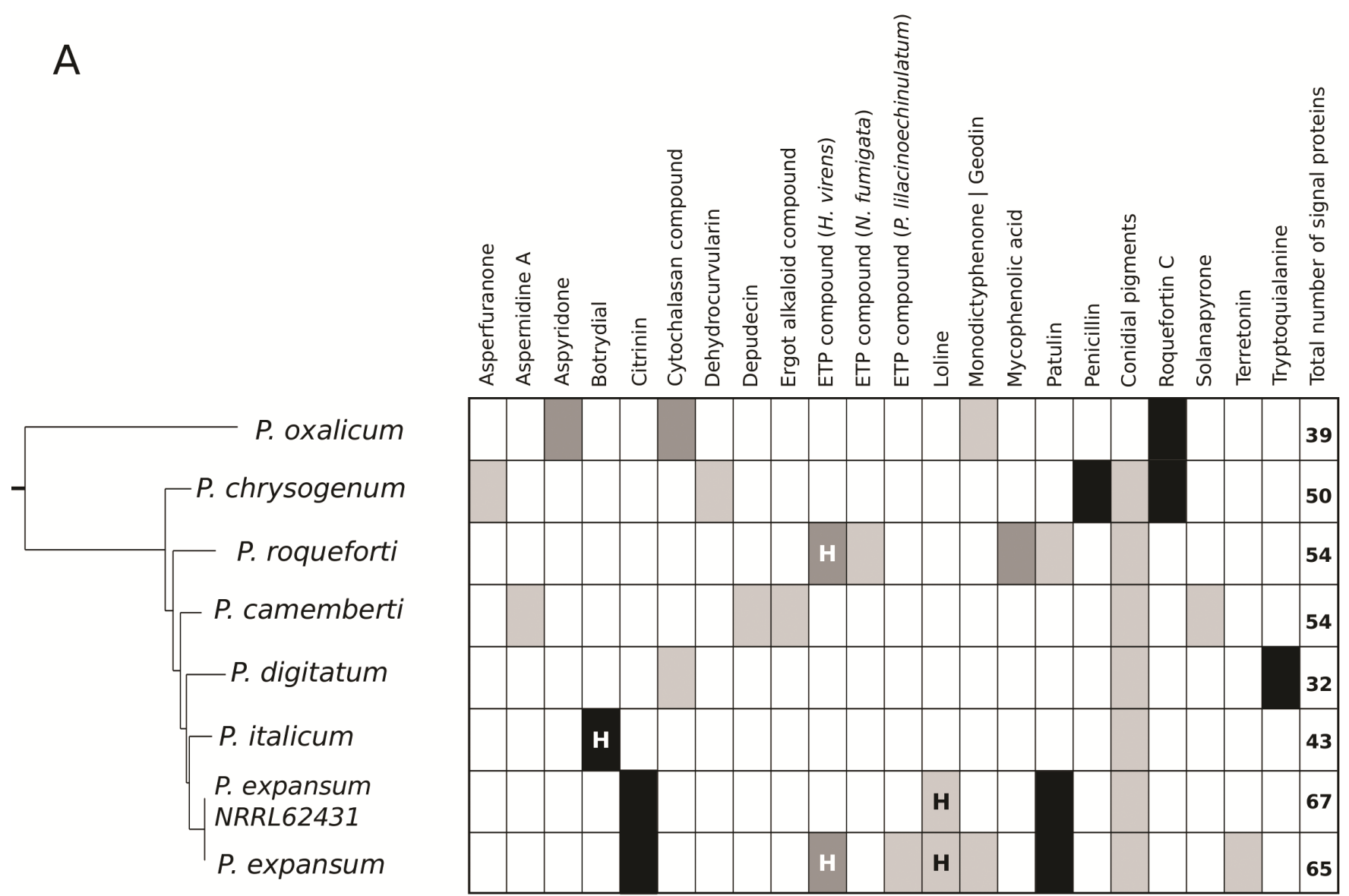

$\mathrm{B}$

Penicillium marneffei

C D

$\mathbf{L}$

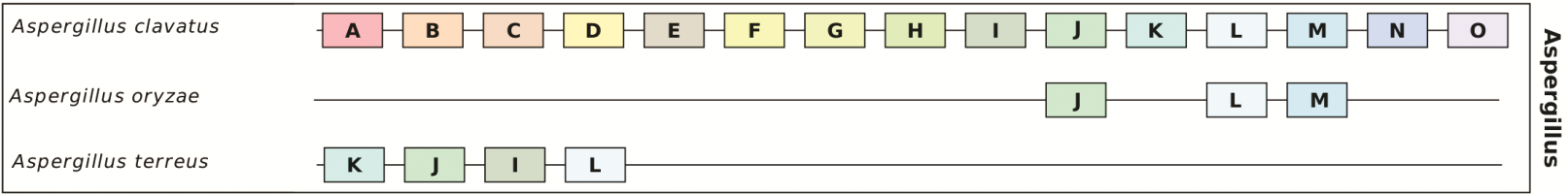

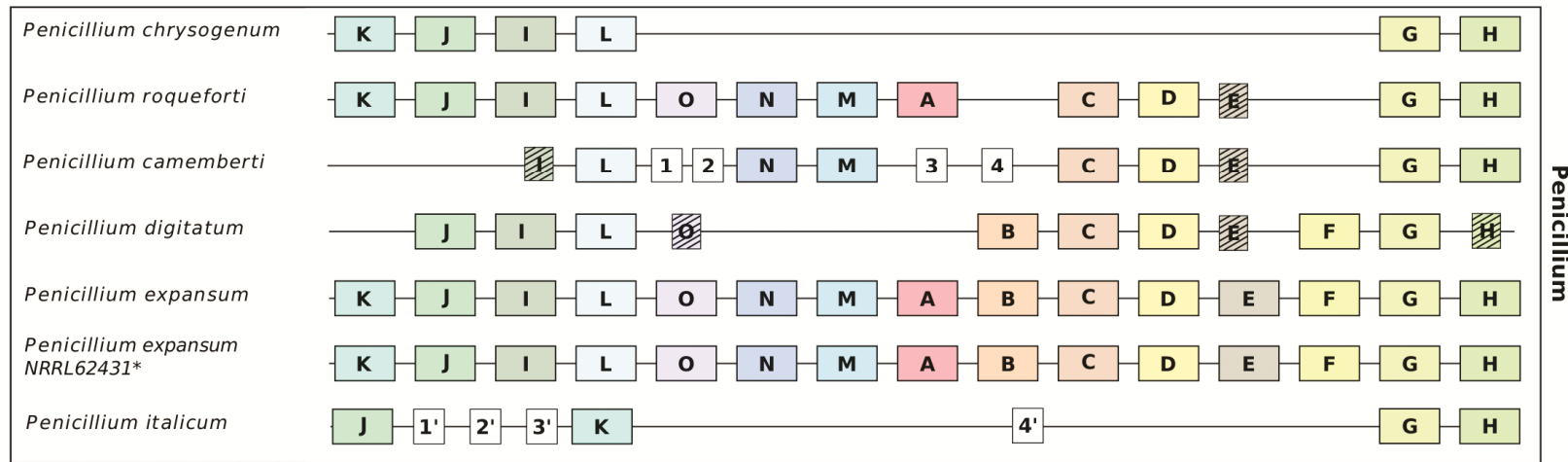

Fig. 2. A, Summary of known secondary metabolism pathways identified in the eight studied Penicillium species. The tree at the left depicts the evolutionary relationships of the Penicillium spp. The table includes the secondary metabolism pathways found in at least one Penicillium species. The different shades indicate the level of conservation of the pathway. Black: all the proteins of the pathway have homologs in that genome. Dark gray: more than 75\% of the proteins have homologs. Light gray: more than $50 \%$ of the proteins have homologs. White: no cluster found. H indicates pathways that are likely to have been transferred through horizontal gene transfer. The last column indicates the number of signal proteins found in each of the Penicillium species. B, Evolution of the patulin gene cluster across Penicillium and Aspergillus species. Each gene is marked by a square and named according to their position in the original cluster described in A. clavatus (Artigot et al. 2009). Stripped squares represent the possible presence of a pseudogene. Additional genes within the cluster are marked with white squares. 
The observed discontinuous distribution of secondary metabolite gene clusters in the Penicillium species examined in the present study could be the result of either differential loss, as shown for patulin, or of HGT. The Pezizomycotina have been found to be particularly prone to acquiring genes through HGT (Marcet-Houben and Gabaldón 2010), and an increasing number of cases involving the transfer of entire metabolic gene clusters have been reported in the literature (Fitzpatrick 2012). A phylogenetic analysis of cases in which the blast hit profiles did not conform with the known species evolutionary relationships (discussed below) was conducted in order to assess whether some of the detected metabolic gene clusters may have resulted from HGT events. Indeed, patterns indicative of HGT were found in at least three of the identified clusters: loline transferred to $P$. expansum (Supplementary Fig. S3), one epipolythiodioxopiperazine (ETP) compound transferred to $P$. expansum and $P$. roqueforti (Supplementary Fig. S4), and botrydial to P. italicum (Supplementary Fig. S5).

\section{Patulin production is impaired in the PEX2 strain.}

PEX2 exhibited distinct differences in colony morphology and sporulation compared with PEXP and PEX1 when grown on potato-dextrose agar (PDA) plates (Fig. 3A and B). PEX2, 7 days postinoculation (dpi), produced 4.8 times fewer conidia per plate as compared with the other two strains (Supplementary Table S5). Additionally, PEXP and PEX1 produced considerable amounts of patulin (approximately 3,000 and 1,000 $\mu \mathrm{g} /$ plate, respectively, at $6 \mathrm{dpi}$ ), whereas PEX2 did not produce any detectable amount of this metabolite (Fig. 3C). The lack of patulin production in PEX2 was not the result of mutations within the coding regions of the genes of the patulin metabolic gene cluster, since all 15 proteins of the cluster in PEXP and PEX2 are identical. In contrast, PEX1, which produces less patulin than PEXP, has a 1- or 2-amino acid difference in four of the patulin cluster proteins. Thus, the phenotypic difference observed in PEX2 is likely caused by a difference in the regulation of the expression of the cluster. To assess whether expression of the cluster was impaired in PEX2, the relative expression levels of three relevant genes, patK coding for 6-methylsalicylic acid synthase, the first enzyme of the patulin pathway, pat $L$ encoding a transcription factor, and pat $N$ coding for a isoepoxydon dehydrogenase, catalyzing one of the last steps of the pathway (White et al. 2006), were measured. The expression profiles of the three genes in PEX2 were significantly different from the expression of those genes in PEXP and PEX1 (Fig. 3D), which is consistent with the observed impairment in the production of patulin on PDA. Significantly, pat $K$ expression is barely detected in PEX2, whereas it is highly induced in the other strains around day 7 . In contrast, pat $N$ and pat $L$ are expressed at higher levels in PEX2 during the first days after inoculation but later decrease significantly or remain level, a pattern that is opposite to that in PEXP and PEX1. Although there are different possibilities to explain the observed misregulation in PEX2, there are some mutations specifically present in the intergenic regions of the patulin gene cluster in PEX2 (Supplementary Table S6). Confirming whether or not these mutations are causing the detected misregulation of the pat genes and the inability to produce patulin, however, will require further experimental verification.

\section{Patulin and citrinin are not directly involved in $P$. expansum pathogenesis.}

While patulin is commonly detected in $P$. expansum-infected apples, there are also reports indicating an absence of patulin in infected apples (Andersen et al. 2004; Martins et al. 2002; Neri et al. 2010). This variability may result from a number of factors that modulate in vivo patulin production and may de- pend either on the fruit variety and degree of ripening, the fungal strain, the presence of additional microbes, or the postharvest storage conditions. Alternatively, the absence of patulin may result from an inability of the fungus to produce it. As previously mentioned, two recent reports (Barad et al. 2014; Sanzani et al. 2012), using either gene-disruption or RNAi mutants, have suggested a direct role of patulin in the level of pathogenicity exhibited by $P$. expansum. In both studies, however, the mutants still produced some level of patulin. The availability of a $P$. expansum strain (PEX2) naturally lacking the ability to produce this compound provided an opportunity to investigate how this phenotype correlates with the ability to infect apples. Thus, infection assays were performed on 'Golden Delicious' apple fruits using the three strains (PEXP, PEX1, and PEX2). All strains behaved similarly and all were able to infect the fruit (Supplementary Fig. S6), demonstrating that the ability to produce patulin is not related to the level of pathogenicity of the Penicillium strain. This premise was further tested by constructing knockout mutants in the PEX1 background for three relevant genes of the patulin gene cluster using Agrobacterium tumefaciens-mediated transformation. The three genes that were the subject of the knockouts were patK, patL, and patN (Fig. 4A). Proper T-DNA integration was checked by polymerase chain reaction (PCR) analysis using locus-specific primers for i) the hygromycin resistance cassette, ii) the correct insertion of the T-DNA between the promoter and the terminator of the target gene, and iii) the absence of the target gene (Fig. 4B; Supplementary Table S7). Confirmation was conducted in one (patL and pat N) or two steps (patK), depending on the size of the target gene. Two independent knockout mutants, each containing a single $\mathrm{T}$ DNA integration (Supplementary Table S8), were selected for further use, along with an ectopic transformant still possessing the wild-type gene. Importantly, deletion of the target genes did not affect growth rate, colony morphology, or sporulation on PDA medium (Fig. 4C). Patulin production was evaluated under conditions supporting its production. No patulin production was detected in any of the $\Delta p a t$ null mutants by days 4 and 7, whereas amounts of patulin similar to those in the wild type were detected in the patK, pat $L$, and pat $N$ ectopic mutants (Fig. 4D). These results confirm the involvement of the predicted genes in patulin biosynthesis. All knockout mutants, when used in apple infection assays, had an ability to infect apples that was similar to the PEX1 wild-type strain and the ectopic transformants (Supplementary Fig. S7).

These results are in contrast to the previously mentioned reports (Barad et al. 2014; Sanzani et al. 2012) that relate patulin production to pathogenicity in $P$. expansum. One of the studies was based on the disruption of patK (Sanzani et al. 2012) and the other on the RNAi-mediated downregulation of patN (Barad et al. 2014). Interestingly, in the former study, pat $K$ was still transcribed in the disruption mutants under patulin-inducing conditions, and patulin production was reduced by just $60 \%$ relative to the parental strain. In the latter study, under in vitro inducing conditions, patulin production was reduced by $87 \%$ in pat $N$ RNAi mutants, but disease incidence in artificially inoculated apple fruits was only reduced by 12 to $28 \%$. Therefore, it is difficult to derive any definitive conclusions from either work. Results of the present study, using two independent gene knockout mutants for either patK, patL, or pat $N$ genes, however, clearly demonstrate that patulin production is not required by $P$. expansum to successfully infect apple fruits under controlled conditions. However, differences in the strains and conditions of the pathogenicity assays may explain, at least in part, the differences observed among the three studies.

Citrinin is another well-known mycotoxin produced by $P$. expansum. The citrinin biosynthetic gene cluster has been identi- 

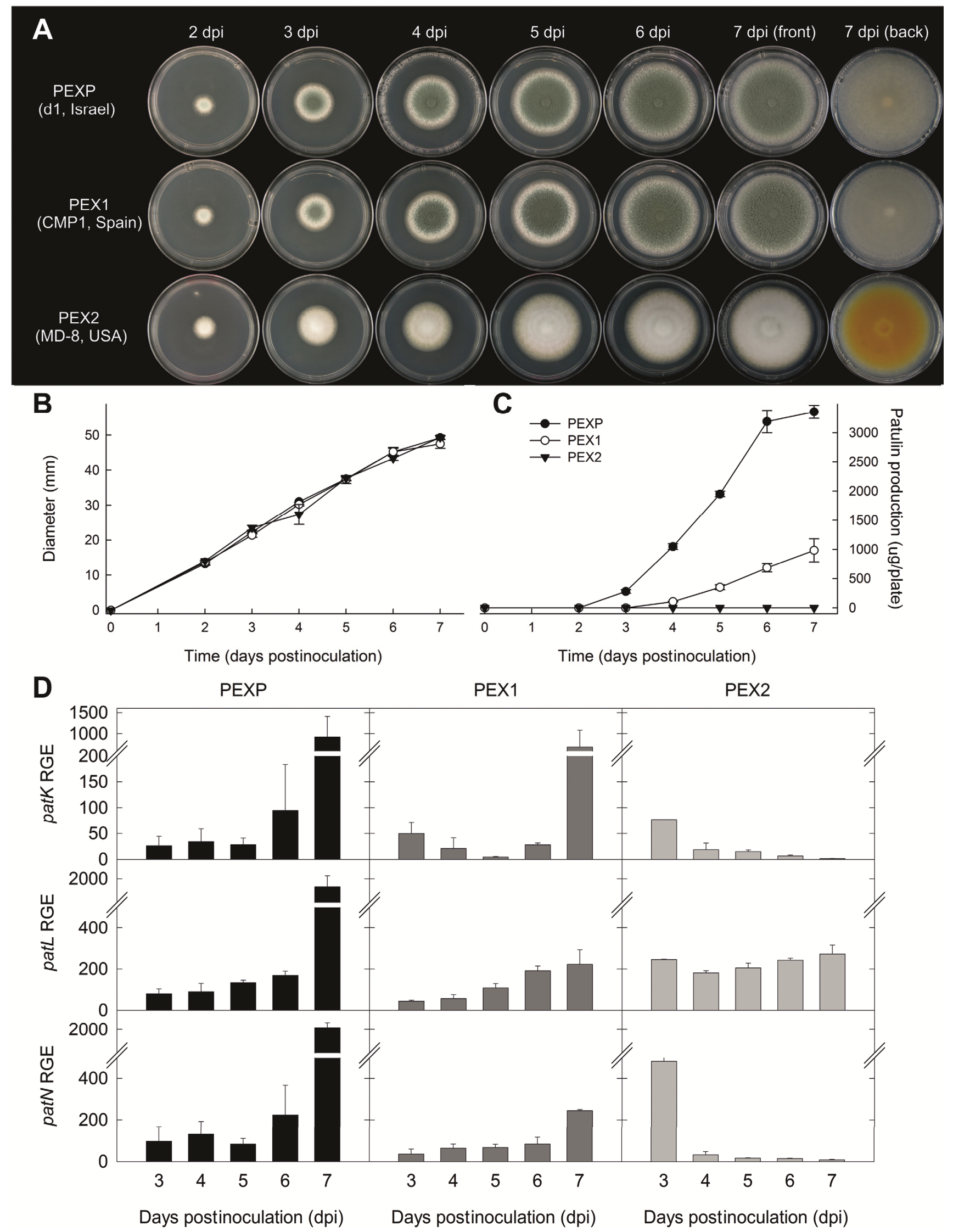

Fig. 3. A, Colony view, B, diameter, C, patulin production, and D, relative gene expression of the three sequenced Penicillium expansum strains. Spore suspensions of strains were inoculated on the center of 55-mm potato dextrose agar (PDA) plates and were incubated for up to 7 days at $24^{\circ} \mathrm{C}$ in the dark. Relative gene expression (RGE) of patK, patL, and pat $N$ in PEXP (black bars), PEX1 (gray bars), and PEX2 (light gray bars) strains after 3, 4, 5, 6, and 7 days of incubation on PDA plates at $24^{\circ} \mathrm{C}$. The expression levels are relative to the $28 \mathrm{~S}$ rRNA and to the genes coding for a histone 3 and $37 \mathrm{~S}$ ribosomal protein s 24. Error bars indicate standard deviations of three biological replicates. 
fied in M. purpureus (Shimizu et al. 2005) and M. aurantiacus (Li et al. 2012). A putative citrinin cluster was identified in the three sequenced $P$. expansum genomes by querying each genome for sequence similarities. The production of citrinin in liquid culture was confirmed (Fig. 5A). Additionally, the expression of the gene $p k s C T$, which encodes a polyketide synthase in the citrinin cluster, was analyzed. This gene had previously been cloned in M. purpureus (Shimizu et al. 2005) and corresponds to PEXP_005520, PEX1_010420, and PEX2_100460. As expected, the gene was expressed in all three strains under citrinin-inducing conditions (Fig. 5B). In order to obtain formal proof of the involvement of pksCT in the production of citrinin, an 8-kb DNA fragment containing the complete gene in $P$. expansum PEX1 was replaced with a hygromycin-resistance cassette following the same procedure used to obtain the pat deletion mutants (Fig. 5C and D). Two knockout transformants were selected, each containing a single T-DNA integration, as determined by the quantification of TDNA copy number. The two selected mutants exhibited no differences in growth rate, morphology, or sporulation, relative to the ectopic mutant and the wild-type strain, when grown on PDA plates (Fig. 5E). Deletion mutants were unable to produce citrinin in liquid medium, whereas citrinin production levels were similar in PEX1 and the ectopic mutant (39.71 and $32.32 \mu \mathrm{g} / \mathrm{ml}$, respectively) (Fig. 5F). This result demonstrates that the PKS encoded by the pksCT gene is required for citrinin production in $P$. expansum, as has already been demonstrated for its ortholog in M. purpureus (Shimizu et al. 2005). Finally, the pathogenicity of the $\Delta p k s C T$ mutants was assessed on inoculated apple fruit under controlled conditions. Results clearly demonstrate that the two knockout mutants were as virulent as the wild-type strain and the ectopic mutant (Supplementary Fig. S8). Similar to patulin, citrinin is also not required for the ability of $P$. expansum to infect apples. It is important to note that all of the infection assays with patulin and citrinin mutants were conducted under laboratory conditions, using fungal inoculum concentrations that typically result in near $100 \%$ disease incidence in just a few days. Thus, a role of patulin and citrinin during infection under natural conditions, where production of mycotoxins by $P$. expansum may help the fungus to outgrow other competing microorganisms, cannot be ruled out. Patulin and, to a lesser extent, citrinin have been shown to be potent antimicrobial compounds (Blanc et al. 1995; Rasmussen and Givskov 2006; Subramani et al. 2013; Zhang et al. 2008).

\section{Transcriptomics of the apple-P. expansum interaction reveals metabolic clusters induced upon infection and putative pathogenicity factors.}

Despite the economic importance of apple blue mold, only a few global transcriptomic studies have been conducted to study the apple $-P$. expansum interaction (Vilanova et al. 2014b), and most of these have focused on identifying differentially expressed genes in apple rather than in $P$. expansum. In order to address this lack of information, an RNA-Seq analysis using apple fruits inoculated with $P$. expansum PEX1 was conducted. RNA was purified from infected tissue at 24, 48, and $72 \mathrm{~h}$ (denoted as 'me24', 'me48' and 'me72', respectively). An additional sample (denoted as 'me0') consisted of a mixture of RNAs from healthy apples and fungal spores obtained after 7 days of growth on PDA medium. A total of 384,181 quality reads (average length of $401 \mathrm{bp}$ ) were generated using the Roche 454 GS FLX Titanium system (Table 2) and were mapped to the genome of both interacting organisms. The number of reads that mapped to the $P$. expansum PEX1 genome increased over time in the tissue samples inoculated with the pathogen, with $2.7 \%$ mapped reads at $24 \mathrm{~h}$ postinoculation (hpi) and up to $70.2 \%$ at 72 hpi. More than $22 \%$ of the reads from the mixed spore and apple sample mapped to the PEX1 genome. Based on the RNA-Seq data, 6,117 of 10,683 predicted genes $(57.3 \%)$ were mapped, with at least two reads in at least one of the four samples.

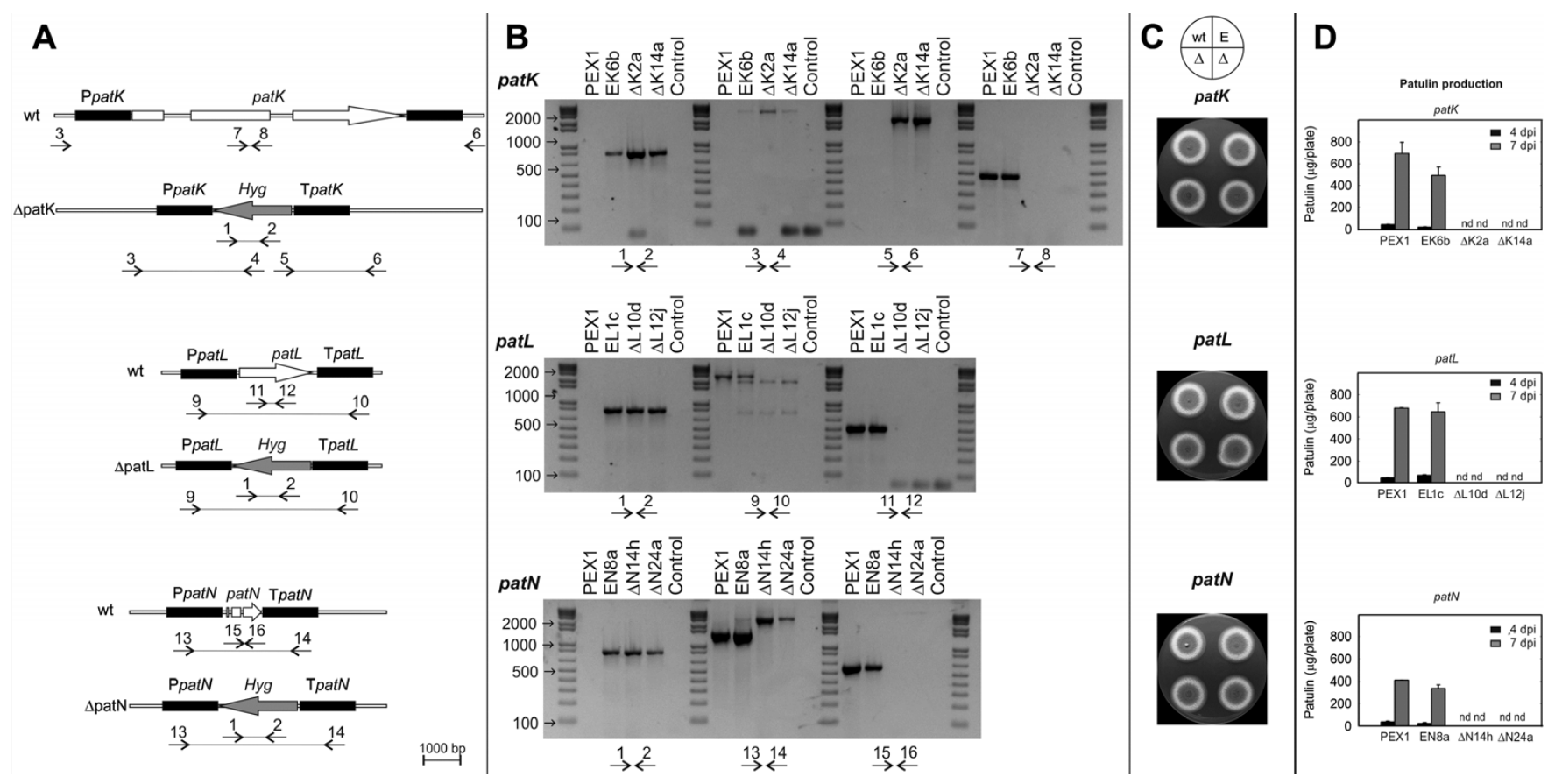

Fig. 4. Deletion of patK, patL, and patN in Penicillium expansum PEX1. A, Diagram of the wild type and deleted patK, patL, and patN loci. The hygromycinselectable marker present in the T-DNA of plasmids pRFHU2-patK, pRFHU2-patL, and pRFHU2-patN replaces the corresponding pat genes by homologous recombination, to generate the $\Delta p a t K, \Delta p a t L$, and $\Delta p a t N$ null mutants, respectively. B, Polmerase chain reaction amplification of the wild type, $\Delta p a t K$, $\triangle p a t L$, and $\triangle p a t N$ null mutants and their respective ectopic mutants with diagnostic primers. C, Colony view of the wild type, ectopic mutants, and two knockout mutants for pat $K$, pat $L$, and pat $N$. D, Patulin production in the wild type, ectopic mutants, and two $\Delta p a t K$, $\Delta p a t L$, and $\Delta p a t N$ mutants during in vitro growth at 4 and 7 days postinoculation (dpi) in PDA medium. 
The expression levels of the 65 genes encoding secondary metabolite signature proteins and their metabolite gene cluster members, as predicted by SMURF (discussed below), were evaluated. Interestingly, two of the highest expression levels were found for the genes PEX1_067120 and PEX1_067130 that belong to the gene cluster involved in the synthesis of an ETP compound that seems to have been acquired by HGT from Hypocrea virens (discussed above). This result was validated by reverse transcription-quantitative (RT-q)PCR of a set of five genes selected from within the ETP cluster (Supple-

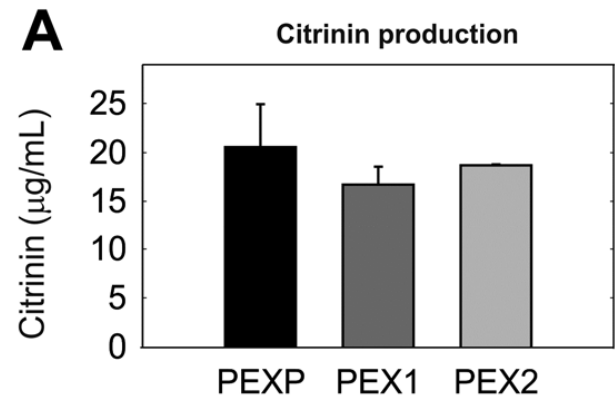

B

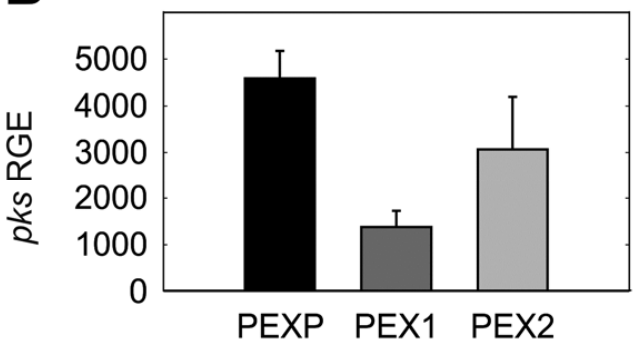

C
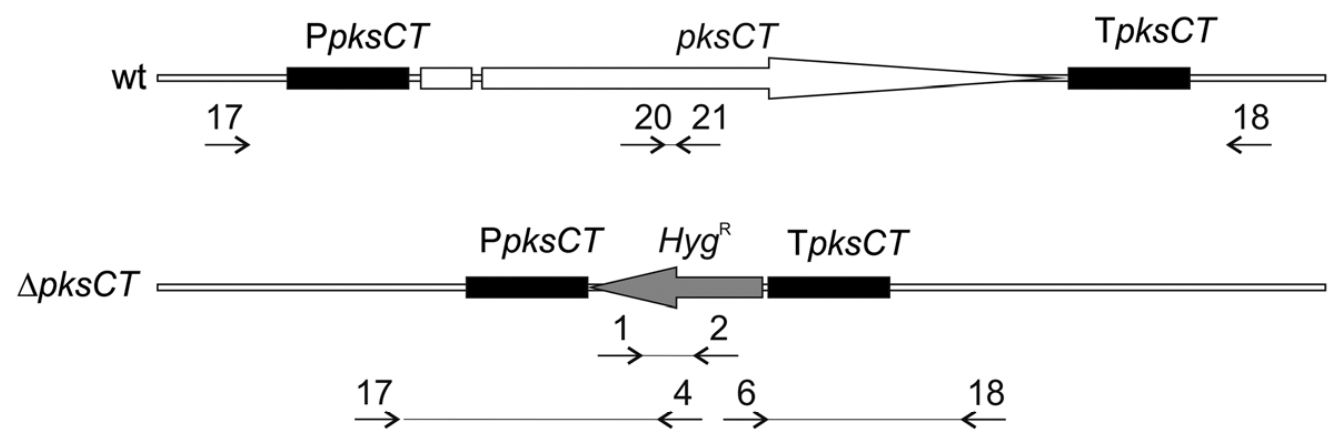

D

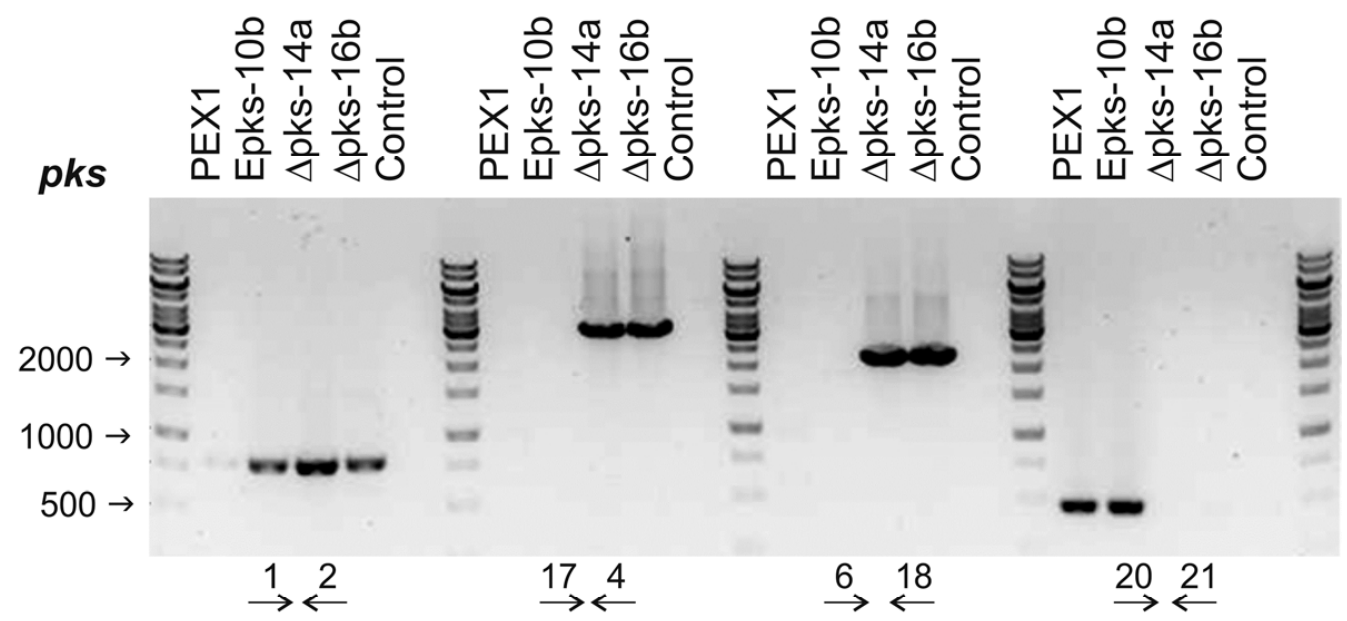

$\mathbf{E}$

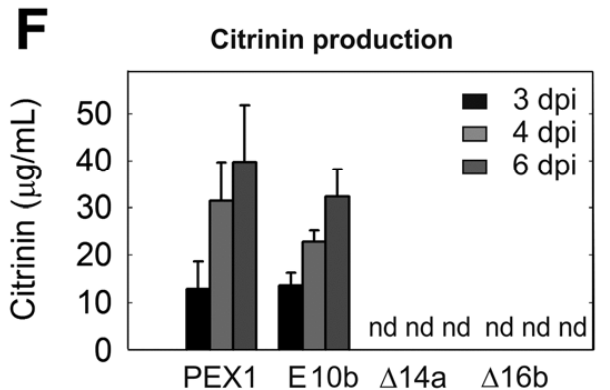

Fig. 5. Citrinin production and deletion of the gene pksCT in Penicillium expansum PEX1. A, Citrinin production in the three sequenced $P$. expansum strains after 7 days of growth in liquid medium. B, Relative gene expression (RGE) of $p k s C T$ in the three P. expansum strains after 7 days of incubation in potato dextrose broth medium. C, Diagram of pksCT replacement with the hygromycin-selectable marker from pRFHU2-pksCT by homologous recombination to generate the $\Delta p k s C T$ null mutants. D, Polymerase chain reaction amplification of the wild type, two $\Delta p k s C T$ null mutants, and the respective ectopic mutant with diagnostic primers. E, Colony view of the wild type, ectopic mutant, and two $\triangle p k s C T$ deletion mutants. F, Citrinin production in the wild type, ectopic mutant, and two $\triangle p k s C T$ deletion mutants during in vitro growth 3,4 , and 6 days postinoculation (dpi). 
mentary Fig. S9). A high correlation $(R=0.802)$ was observed between the expression values measured by RNA-Seq and RTqPCR. The expression of genes from 20 putative metabolic clusters was detected during the sampled infection period. Interestingly, in 15 of the clusters, the expression of the signature protein was detected exclusively under infection conditions and, in nine of them, the specific expression was found for at least half of the genes in the cluster. Expression levels could, in some cases, be used to define the boundaries of the clusters initially predicted by SMURF. For instance, cluster number 46 is predicted to contain 20 genes by SMURF, but five of the last six genes of the cluster are not expressed, while nine of the 14 remaining genes are expressed during infection. This suggests that the actual length of the cluster is 14 genes rather than the 20 predicted by SMURF.
Global gene-expression profiles were then placed in functional categories (discussed below). Five functional categories showed at least a twofold higher representation at 24 hpi (Fig. 6 ). These were ribosome, exosome, protein phosphatases and associated proteins, ubiquitin system and DNA repair, and recombination proteins. These results indicate that the fungus is actively growing during this early phase of host colonization. The high abundance of proteins related to exosomes is notable. Exosomes form via invagination of membranes and subsequent formation of multivesicular bodies. Studies over the past few years have reported that many fungal proteins located outside the cell lack a signal peptide and that secretion of these proteins may be achieved by extracellular vesicles. This mechanism represents an alternative pathway to the classical endoplasmic reticulum/Golgi-dependent secretion system (Rodrigues et al.

Table 2. Summary of RNA-Seq results

\begin{tabular}{|c|c|c|c|c|}
\hline Variable & me0 & me24 & me48 & me72 \\
\hline No. sequenced reads & 72,302 & 51,182 & 86,568 & 174,129 \\
\hline \multicolumn{5}{|l|}{ Malus domestica: } \\
\hline Total gene reads & $46,501(64.3 \%)$ & $40,740(79.6 \%)$ & $42,209(48.8 \%)$ & $32,130(18.5 \%)$ \\
\hline \multicolumn{5}{|l|}{ Penicillium expansum PEX1: } \\
\hline Total gene reads & $16,497(22.8 \%)$ & $1,364(2.7 \%)$ & $31,484(36.4 \%)$ & $122,239(72.0 \%)$ \\
\hline No. genes mapped ( $\geq 2$ reads) & 1,986 & 205 & 2984 & 5,611 \\
\hline DGE $\left(\geq 2\right.$ reads, $\log _{2} \geq 1$, and FDR-corrected $P$ values $\leq 0.05^{\mathrm{a}}$ & & 181 & 2,125 & 4,469 \\
\hline
\end{tabular}

${ }^{\mathrm{a}} \mathrm{DGE}=$ differential gene expression; FDR $=$ false discovery rate.

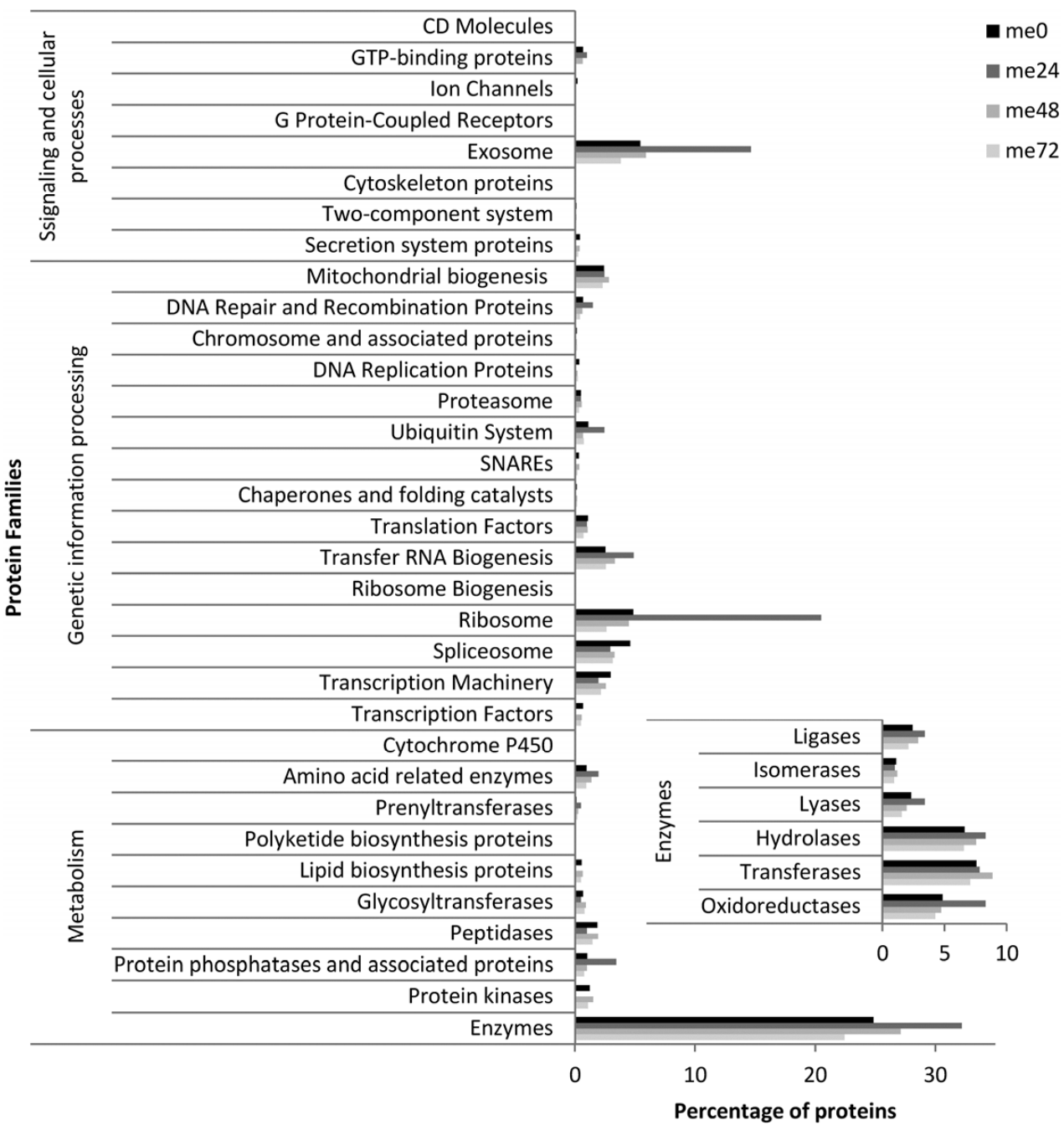

Fig. 6. Functional classification of proteins detected in spores and during the infection of apples by Penicillium expansum PEX1, based on the KEGG orthology database, using KAAS (KEGG automatic annotation server). 
2013). Importantly, fungal pathogens may use this alternative system to deliver effectors (Donofrio and Raman 2012). In fact, ten proteins were identified that have been described as being extracellularly located in $P$. expansum grown in liquid medium (Qin et al. 2007), seven of which lack a signal peptide. At later stages of infection (48 to $72 \mathrm{hpi}$ ), other categories classically associated with pathogenesis, such as glycosyltransferases, were more abundant. At 24 hpi, "Translation, ribosomal structure and biogenesis" was also the most differentially expressed category indicated in the KOG classification system (Supplementary Fig. S10).

Relative to gene expression in spores, 181, 2,125, and 4,469 differentially expressed genes (two or more reads, absolute $\log _{2} \geq 1$, and false discovery rate (FDR)-corrected $P$ value $\leq$ 0.05 ) were detected at the three time points sampled after inoculation with $P$. expansum $(24,48$, and 72 hpi). These results must be interpreted with caution, especially for those corresponding to the initial stages of infection when the number of reads for the fungus is rather low. Nevertheless, these comparisons can provide useful insights to the processes relevant to host-pathogen interactions. Gene Ontology (GO) enrichment analysis of differentially expressed genes (Supplementary Table S9) indicates that ribosome biogenesis and translation were the most significantly enriched biological processes in the set of genes upregulated at both 24 and 48 hpi, whereas ATP-binding was the most significant molecular function. At 48 and 72 hpi, there is an over-representation of metabolic processes for different amino acids, gluconeogenesis, and mitosis. Interestingly, several processes related to transcription were downregulated at these two time points.

A closer examination of the genes upregulated during the infection process highlights an abundance of genes associated with pathogenicity, such as proteases, cell wall-degrading enzymes (CWDE), and oxidoreductases. Although different proteases reach their maximum expression at different times after fungal inoculation, the highest expression values were found within the subset of proteases that peak at $24 \mathrm{hpi}$ and PEX1_081750, coding for an aspergillopepsin, was the most highly expressed protease at all time points (Supplementary Fig. S11A). Interestingly, the orthologous gene in P. digitatum is also highly expressed during infection of citrus fruit (LópezPérez et al. 2014). The RNA-Seq results confirmed the upregulation of two previously identified polygalacturonase-encoding genes (Sánchez-Torres and González-Candelas 2003) and their patterns of expression. Other previously undescribed pectinaseencoding genes, like PEX1_083670 and PEX1_055640, which encode a pectate lyase and a polygalacturonase, respectively, also showed a very high expression level during infection of apple fruit. All the pectinase-encoding genes reached their maximum expression within the first 48 hpi. Other highly expressed CWDE-encoding genes are the glycosyl hydrolases glucanases and xylanases. Notably, among these enzymes only the expression of one endo-1,4-beta-xylanase (PEX1_085560) was detected, which was induced at 48 and 72 hpi. Several of the glycosyl hydrolases increased their expression as infection progressed, reaching a maximum at 72 hpi. It has been reported that alteration of the redox status in $P$. expansum affects its ability to infect host tissues and that a rapid adaptation to a stressful redox environment is a limiting factor determining the establishment of infection in the apple- $P$. expansum pathosystem. Proteins with antioxidant activity, such as catalase and superoxide dismutase (SOD), have been reported to be involved in the pathogenicity of $P$. expansum (Tian et al. 2013). In the current study, the expression of different catalase- and SOD-encoding genes was indeed observed. The six catalases annotated in PEX1 were expressed at least one time point. One of them, PEX1_064380, was specifically expressed in spores, and several catalases peaked in expression at 24 hpi. SOD-encoding genes, however, exhibited reduced expression, in terms of both the number of expressed genes and their relative expression level.

One of the proposed mechanisms of pathogenicity in $P$. expansum involves fungal-induced acidification of the host tissue. This acidification ensures the synthesis and optimal activity of secreted CWDE that macerate the host tissue. In $P$. expansum, the acidification is driven by the secretion of different organic acids (Prusky et al. 2004; Vilanova et al. 2014a). The accumulation of gluconic acid parallels the development of the fungus within the fruit. In this regard, two glucose oxidase-encoding genes have been described in P. expansum, goxl and gox 2 (Hadas et al. 2007). Gox 2 has been shown to be responsible for gluconic acid accumulation and acidification of apple tissue during colonization (Barad et al. 2012). Moreover, gox2 RNAi mutants were impaired in pathogenicity. Twelve putative glucose oxidase-encoding genes were identified in $P$. expansum in the present study, including the previously described gox1 and gox2 genes, PEX1_007110 and PEX1_007490, respectively. The RNA-Seq data revealed that only two gox genes were expressed during infection. These were gox 2 and PEX1_011780 (designated as gox3). Based on the presence of a signal peptide, both Gox proteins are presumed to be extracellular. The expression of gox3 was eight- and10-fold higher than gox2 at 48 and 72 hpi, respectively, and gox3 was the only expressed gox gene at 24 hpi. This expression pattern suggests that Gox 3 could play an important role in pathogenicity via the extracellular production of gluconic acid.

Other proteins relevant to pathogenicity are the so-called effector proteins, which are able to modulate host physiology in order to avoid recognition and thus facilitate colonization (de Jonge et al. 2011; Kombrink and Thomma 2013). The majority of fungal and oomycete effectors have been characterized in biotrophic and hemibiotrophic pathogens; however, necrotrophic fungi also produce effectors in addition to host-specific toxins (Condon et al. 2013; Guyon et al. 2014; Vleeshouwers and Oliver 2014). The repertoire of putative $P$. expansum effectors is unknown. The present study focused on two well-known families of putative effectors: secreted proteins containing a chitin binding domain (LysM domain), and hypothetical, small secreted, cysteine-rich proteins, as this is a shared characteristic in many effectors that do not share sequence conservation. In PEX1, only one of the 17 annotated genes encoding proteins containing a LysM domain (PEX1_045470) showed a high level of expression during the infection process. Most of the small, secreted, cysteine-rich proteins showed low or no expression during infection. Only two genes (PEX1_040580 and PEX1_ 096670) showed a very high level of expression in the spore samples or samples collected shortly after inoculation. PEX1_ 096670 corresponds to a previously identified gene specifically expressed in the apple- $P$. expansum interaction (GenBank accession number AJ518007) (Sánchez-Torres and GonzálezCandelas 2003). PEX1_045470 is only expressed in spores. This latter gene seems to be specific to $P$. expansum, as no homologs could be identified in any of the current databases. Overall, the RNA-Seq results highlight the arsenal of putative pathogenicity factors deployed by $P$. expansum during infection of apple fruit and identify specific candidates that should be functionally analyzed in order to further understand their role in the pathogenicity of $P$. expansum.

\section{Concluding remarks.}

Our results clearly establish that $P$. expansum strains unable to produce patulin or citrinin do not show any observable reduction in virulence under controlled conditions. This indicates that these two toxins are not directly required to establish 
an infection in apple fruit. The potential that these toxins may have a significant effect under noncontrolled, natural conditions, such as in the presence of competing microbes, cannot be ruled out. Determining the possible role of these toxins under the wide array of conditions naturally encountered by this species will require additional experiments. Notably, our analysis identified a set of metabolite gene clusters that are expressed (sometimes specifically) during infection, which opens interesting avenues of research that will be needed to determine whether or not these other metabolites have a role in the infection process and pathogenicity. Finally, the comparative analysis of sequenced Penicillium genomes conducted in the present study revealed a highly dynamic genome content, with expansions and contractions and with a potential, prominent role for horizontal transfer in the acquisition of some metabolite gene clusters. Interestingly, in the case of pathogenic Penicillium species, smaller genomes tend to be associated with reduced host range.

\section{MATERIALS AND METHODS}

\section{Fungal strains.}

Penicillium expansum Link isolate d1 from Israel (denoted as PEXP), CMP-1 from Spain (denoted as PEX1), and isolate MD-8 from the United States (denoted as PEX2) were used in this study. PEXP was isolated from decayed apple fruit following three months of storage and was kept on PDA at $4^{\circ} \mathrm{C}$. PEX1 was isolated from a decayed 'Golden' apple after several months in storage in Lleida (Spain) (Teixidó et al. 1998), and PEX2 (provided by W. Janisiewicz) was isolated from decayed apple kept in cold storage for approximately five months and was maintained on PDA with periodic transfer through apple and is the most aggressive strain at the Appalachian Fruit Research Station, United States Department of AgricultureAgricultural Research Station, Kearneysville, WV, U.S.A. (Janisiewicz et al. 1992). Penicillium italicum Wehmer PHI-1 (denoted as PITC) was isolated from a mandarin stored at $4{ }^{\circ} \mathrm{C}$ in Valencia (Spain). Strains have been deposited in the Spanish Type Culture Collection (CECT) with accession codes CECT 20907 for $P$. expansum isolate d1, CECT 20906 for CMP-1, CECT 20908 for MD-8, and CECT 20909 for P. italicum PHI-1.

\section{Genomic DNA extraction.}

Genomic DNA of $P$. expansum PEX1 and $P$. italicum was extracted as previously described by Marcet-Houben and associates (2012). Briefly, $5 \times 10^{5}$ conidia/ml were grown in 500 $\mathrm{ml}$ of potato dextrose broth media (PDB) (Difco) on a shaker at $180 \mathrm{rpm}$ at $24^{\circ} \mathrm{C}$ for 4 days. Fungal mass was collected, dried, and frozen in liquid nitrogen. DNA was extracted from $1 \mathrm{~g}$ of frozen mycelium. The final DNA preparation was incubated overnight at room temperature in $490 \mu \mathrm{l}$ of Tris-EDTA (TE) buffer and $10 \mu \mathrm{l}$ of DNase-free RNase $(10 \mu \mathrm{g} / \mathrm{ml})$, followed by phenol-chloroform extraction and isopropanol precipitation. Finally, DNA was resuspended in TE buffer. Genomic DNA of PEXP and PEX2 was extracted following the protocol described by Al-Samarrai and Schmid (2000). Fungal mycelial mass was obtained as described above and was freeze dried. DNA extracted from the freeze dried mycelium was suspended in $500 \mu \mathrm{l}$ of TE buffer. DNA quality was assessed by spectrophotometry (NanoDrop) and gel electrophoresis (data not shown).

\section{Genome sequencing.}

$P$. expansum PEX1 and $P$. italicum PITC genomes were sequenced at the Ultra-Sequencing core facility of the Centre for Genomic Regulation (Barcelona, Spain). To prepare the libraries, DNA was fragmented by nebulization or in Covaris to approximately $600 \mathrm{bp}$ in size. After shearing, the ends of DNA fragments were blunted with T4 DNA polymerase and Klenow fragment (New England Biolabs). Then, DNA was purified with a QIAquick PCR purification kit (Qiagen). Thereafter, 3' adenylation was performed by incubation with dATP and a $3^{\prime}$ to $5^{\prime}$-exo-Klenow fragment (New England Biolabs). DNA was purified using MinElute spin columns (Qiagen), and doublestranded Illumina paired-end adapters were ligated to the DNA, using rapid T4 DNA ligase (New England Biolabs). After another purification step, adapter-ligated fragments were enriched, and adapters were extended by selective amplification in an 18-cycle PCR reaction, using Phusion DNA polymerase (Finnzymes). Libraries were quantified and loaded into Illumina flow cells at concentrations of 7 to $20 \mathrm{pM}$. Cluster generation was performed in an Illumina cluster station. Sequence runs of $2 \times 100$ (PEXP and PEX2 strains) or $2 \times 55$ (PEX1) cycles were performed on the sequencing instrument. Base calling was performed using Illumina pipeline software. In multiplexed libraries, we used 4-bp internal indices ( $5^{\prime}$ indexed sequences). Deconvolution was performed using the CASAVA software (Illumina).

\section{Genome assembly and functional annotation.}

Reads were filtered using a quality threshold of 10 and a minimum read length of 31 when reads were trimmed. Genomes were then assembled using SOAP de novo (Luo et al. 2012). GapCloser was used to fill in the gaps in the scaffolds. $P$. expansum genomes were annotated using Augustus (Stanke et al. 2006), making use of the RNA-Seq data. The basic annotation was complemented by a homology-based search in which proteins found in the UniProt database (The UniProt Consortium 2014) were compared with the genomes using GeneWise (Birney et al. 2004). Those genes that did not overlap with the Augustus annotation were added to the annotation. Finally, a comparison was run among the three $P$. expansum strains in order to unify predictions when possible. The annotation of $P$. italicum was done similarly, with the exception that RNA-Seq data was not available. For each predicted protein, GO, KEGG, InterPro, and Enzyme Code annotations were assigned by using Blast2GO (Conesa et al. 2005). Functional annotation of the predicted proteins was performed by using the KOG database at the Web server for the MetaGenomic Analysis (WebMGA) (Wu et al. 2011) and by using the KEGG automatic annotation server (Moriya et al. 2007). Carbohydrate-active enzymes (CAZymes) were identified by using the CAZymes analysis toolkit (CAT) (Lombard et al. 2014; Park et al. 2010) and dbCAN, a web server and database for automated CAZyme Annotation (Yin et al. 2012).

\section{Phylogenomic analyses.}

Phylome reconstruction. Phylomes, the entire collection of phylogenetic trees for each gene in a genome, were reconstructed for each of five Penicillium species ( $P$. chrysogenum, $P$. oxalicum, $P$. expansum, $P$. italicum, and $P$. digitatum). Nineteen other Pezizomycotina species were included for the phylome reconstruction. The phylomes were reconstructed using an automatic approach that mimics the steps taken to reconstruct a single phylogenetic tree: homology search, multiple sequence alignment, and finally, phylogenetic reconstruction, essentially as described before (Huerta Cepas and Gabaldón 2011). Briefly, for each protein-coding gene encoded in a Penicillium genome, we perform a Smith-Waterman search, using the protein sequence as a query, against the database formed by 24 proteomes. Results are then filtered according to $\mathrm{E}$ value $(<1 \mathrm{e}-05)$ and continuous overlapping region $(>0.5)$. Number of hits considered is limited to the most similar 150. Multiple sequence alignments are then reconstructed for each 
group of homologs, using three different programs: MUSCLE v3.8 (Edgar 2004), MAFFT v6.712b (Katoh et al. 2005), and Kalign (Lassmann and Sonnhammer 2005). Alignments are performed in forward and reverse direction and the six resulting alignments are then combined in a consensus alignment using M-Coffee (Wallace et al. 2006). This combined alignment is then trimmed using trimAl v1.3 (consistency score cutoff $=0.1667$, gap-score cut-off $=0.9$ ) (Capella-Gutierrez et. al 2009). The last step is to reconstruct the phylogenetic tree, so first we selected the evolutionary model that best fit our data. A neighbor-joining tree was reconstructed as implemented in BIONJ, and then, the likelihood of this topology was computed, allowing branch-length optimization, using seven different models (JTT, LG, WAG, Blosum62, MtREV, VT, and Dayhoff), as implemented in PhyML v3.0 (Guindon et al. 2010); the two models best fitting the data following the AIC criterion were used to derive ML trees. Four rate categories were used and invariant positions were inferred from the data. Branch support was computed using an approximate likelihood ratio test based on a chi-square distribution. The five phylomes have been deposited in phylomeDB (Huerta-Cepas et al. 2014) with the phyID numbers 279 to 283. Eight additional phylomes were reconstructed with a closer focus on Penicillium species. In this case, the eight Penicillium species included were supplemented with four Aspergillus species and two Talaromyces species. These phylomes are stored in phylomeDB with phyID numbers 357 to 364 .

Species tree reconstruction. Data from the P. expansum phylome was used to reconstruct the species tree. We selected 844 single-copy genes that were present in the 24 species contained in the phylome. A similarity search of these 844 single-copy genes was then performed against the two additional Penicillium genomes that were not included in the large phylome ( $P$. roqueforti and $P$. camemberti). Only the 524 proteins that had one single hit in each of these species were used to reconstruct the species tree. The final alignment contained 340,352 positions. RAxML v7.2.6 (Stamatakis et al. 2012) was used to reconstruct the species tree using the PROTGAMMALG model. Bootstraps were run using RAxML. All the nodes in the tree had a bootstrap value of 100. A second tree was reconstructed based on the smaller phylome. A total of 2,147 single-copy genes were found based on the phylome and were concatenated. The alignment consisted of 1,474,982 amino-acid positions. The tree was reconstructed in the same way as the previous one. Bootstrap values are of 100 . Both topologies are completely congruent regarding the species they share.

Gene gain or loss. Trees reconstructed in each phylome were analyzed using ETE v2 (Huerta-Cepas et al. 2010). For each tree, orthology predictions were made using a species overlap algorithm. This approach consists of calling duplication and speciation nodes depending on the overlap of species found in a given node. If no overlap is found, a speciation node is called and, therefore, the sequences are orthologous. Once the orthology relationships were calculated, for each phylome, we could count the number of gene gains and gene losses that occurred at each node of the Penicillium species tree. A gene gain was inferred in a given node in the Penicillium species tree if it did not appear in any of the species that diverged before that node. A gene loss was inferred when a gene did not have an ortholog in a particular Penicillium species. Speciesspecific gene gains were identified by scanning the similarity search result performed in the phylome reconstruction. Any gene that did not contain a homolog in any of the other species was considered as gained.

Specifically duplicated proteins. The phylome was scanned to look for nodes in which two or more sequences of the same species were located without any other species. Two lineage- specific expansion groups were fused if they shared over $50 \%$ of their members.

Detection of secondary metabolism clusters. We scanned the eight Penicillium species for the presence of 98 known secondary metabolism clusters. For each one of the clusters, the sequence of the proteins encoded by the genes in the seed cluster was obtained and a blast search was performed against each of the eight Penicillium proteomes. Hits were filtered for E value $(<1 \mathrm{e}-05)$ and continuous overlapping region $(>0.5)$. For the hits that passed the filter, gene order information was introduced. The cluster was considered to be present when more than half of the proteins encoded by the genes present in the cluster had homologs in a given Penicillium species and these homologs were found close to each other, allowing up to three genes to be found in between two cluster homologs. At least three genes needed to be found together in order to consider the cluster. The order of the genes in the cluster was not considered, due to the high variability of gene order found in functionally equivalent clusters present in different fungi. Metabolic clusters found in Penicillium species that had homologs in other fungal groups were considered for HGT analysis. For each gene in the cluster, a protein tree was reconstructed-using the pipeline described above-that included the original protein, the Penicillium protein, and up to 50 most similar homologs in other fungal species. Single trees were analyzed manually for HGT signatures. In parallel, secondary metabolism clusters were also predicted using SMURF (Khaldi et al. 2010).

SNP detection. Reads were mapped onto the reference genome (PEXP) using bwa (Li and Durbin 2009). SNP were identified using GATK (McKenna et al. 2010), using thresholds for mapping quality $(>50)$ and read depth $(>10)$; also, SNP had to appear in forward and reverse reads. A total of 44,482 and 59,535 SNP were detected in PEX1 and PEX2, respectively.

\section{Pathogenicity assays.}

The pathogenicity of $P$. expansum wild-type and transformant strains was examined by inoculation of 'Golden Delicious' apples (Malus $\times$ domestica Borkh), obtained from a local grocery. Apples were submerged for $5 \mathrm{~min}$ in a $5 \% \mathrm{com}-$ mercial bleach solution, were rinsed extensively with tap water, and were allowed to dry at room temperature. Fruits were wounded with a sterilized needle ( $3 \mathrm{~mm}$ in depth) and were immediately inoculated by adding $10 \mu \mathrm{l}$ of $P$. expansum conidia suspension adjusted to $10^{4}$ conidia/ml. Three replicates of five infected fruit with four wounds per fruit were placed on plastic boxes and were incubated at $20^{\circ} \mathrm{C}$ and 90 to $95 \%$ relative humidity. Disease incidence was determined at $5 \mathrm{dpi}$ as the percentage of infected wounds. Analysis of variance was performed to test the different incidence among strains. Means were separated using Tukey's test with $P<0.05$, using Statgraphics Plus 5.1 (Manugistics Inc.).

\section{RNA extraction from $P$. expansum-infected apple tissue.}

Total RNA was extracted from $P$. expansum-infected apple fruit tissue at different times after inoculation. For each sample, $1 \mathrm{~g}$ of lyophilized tissue was ground in liquid nitrogen, using a mortar and pestle. The ground powder was dissolved in $10 \mathrm{ml}$ of extraction buffer ( $2 \%$ cetyltrimethylammonium bromide, $2 \%$ polyvinylpyrrolidone, $0.1 \mathrm{M}$ Tris- $\mathrm{HCl}$ ( $\mathrm{pH} 8.0), 25$ mM EDTA, $2 \mathrm{M} \mathrm{NaCl}, 2 \% \beta$-mercaptoethanol) preheated to $65^{\circ} \mathrm{C}$. After mixing for $2 \mathrm{~min}$ by vortex, the samples were incubated at $60^{\circ} \mathrm{C}$ for $15 \mathrm{~min}$ and were mixed occasionally. After incubation, an equal volume of chloroform:isoamyl alcohol (Chl:Iaa) (24:1) was added to each sample, was mixed by vortex for $2 \mathrm{~min}$, and was centrifuged at $12,000 \times g$ for $20 \mathrm{~min}$ at $4{ }^{\circ} \mathrm{C}$. The upper phase was transferred to a clean tube, and the RNA was re-extracted with an equal volume of Chl:Iaa. 
The supernatant was transferred to a clean 50-ml tube, was mixed with $1 / 3$ volume of $7.5 \mathrm{M} \mathrm{LiCl}$, and was incubated overnight at $4^{\circ} \mathrm{C}$. RNA was precipitated by centrifugation at $12,000 \times g$ for $50 \mathrm{~min}$ at $4^{\circ} \mathrm{C}$. The pellets were washed with 5 $\mathrm{ml}$ of $75 \% \mathrm{EtOH}$, were air dried, and were dissolved in $500 \mu \mathrm{l}$ SSTE buffer (0.5\% SDS, $1 \mathrm{M} \mathrm{NaCl}, 10 \mathrm{mM}$ Tris-HCl (pH 8), $1 \mathrm{mM}$ EDTA) preheated to $65^{\circ} \mathrm{C}$. The RNA was re-extracted again by adding an equal volume of Chl:Iaa, mixing by vortex for $2 \mathrm{~min}$, and centrifugating at $14000 \times g$ for $10 \mathrm{~min}$ at $4^{\circ} \mathrm{C}$. The upper phase was transferred to a clean microcentrifuge tube. RNA was precipitated by addition of 2 volumes of $100 \%$ $\mathrm{EtOH}$, incubation at $-80^{\circ} \mathrm{C}$ for $30 \mathrm{~min}$, and centrifugation at $14000 \times g$ for $20 \mathrm{~min}$ at $4^{\circ} \mathrm{C}$. The pellets were washed by $1 \mathrm{ml}$ of $75 \%$ ethanol, were air dried, and were dissolved in $50 \mu \mathrm{l}$ of nuclease-free water. Quality and concentration of total RNA was analyzed by gel electrophoresis and spectrophotometry (ND-1000, NanoDrop), respectively.

\section{RNA-Seq analysis.}

RNA-Seq data were generated from four different libraries: a cDNA library synthesized from a mixture of RNAs obtained from $P$. expansum PEX1 spores collected after 7 days of growth in PDA and healthy, noninoculated fruits, and three libraries from $P$. expansum-infected apples at 24, 48, and $72 \mathrm{hpi}$, respectively. Fruit inoculation was conducted following the procedure previously described (Sánchez-Torres and González-Candelas 2003). In brief, 'Golden Delicious' apples (Malus $\times$ domestica Borkh) were obtained from a local grocery. Apples were dipped for $5 \mathrm{~min}$ in a 5\% commercial bleach solution, were rinsed extensively with tap water, and were allowed to dry at room temperature. Fruits were wounded with a sterilized needle $(3 \mathrm{~mm}$ in depth) and were immediately inoculated by adding $10 \mu \mathrm{l}$ of $P$. expansum conidia suspension adjusted to $10^{6} \mathrm{conidia} / \mathrm{ml}$. Three replicates of five infected fruit with twelve wounds per fruit were placed on plastic boxes and were incubated at $20^{\circ} \mathrm{C}$ and 90 to $95 \%$ relative humidity. Tissue discs of $7 \mathrm{~mm}$ around the inoculation point were sampled using a cork borer and were immediately frozen in liquid nitrogen, mixed, ground to a fine powder with a coffee mill, and stored at $-80^{\circ} \mathrm{C}$ until RNA extraction. For each sample, total RNA from the three biological replicates was mixed and used to construct the cDNA, using the MINT-Universal cDNA synthesis kit (Evrogen), following the manufacturer's protocol. Sequencing was carried out using the Roche 454 GS FLX Titanium system. All high-quality reads for each sample were analyzed with the RNA-Seq analysis program of the CLC Genomics Workbench software (CLCbio) and were mapped to the predicted gene models of $P$. expansum PEX1 and Malus $\times$ domestica Borkh (Velasco et al. 2010). At least $80 \%$ of the bases were required to align to the reference and a maximum of two mismatches were allowed. Only genes that were detected in at least one sample, with two or more reads mapped, were used in the analysis. Identification of differentially expressed genes was based on normalized gene expression values calculated as reads per kilobase of exon model per million mapped read (Mortazavi et al. 2008) and were analyzed using the Kal's test (Kal et al. 1999). Genes were considered differentially expressed if they possessed two or more reads and absolute value of $\log _{2}$ (fold change) $\geq 1$ and an adjusted FDR $P$ value $\leq 0.05$. An enrichment analysis based on Fisher's exact test implemented at Blast2GO (Conesa et al. 2005) was used to extract GO terms that were significantly over- or under-represented in a particular set of genes relative to a reference group composed of all PEX1 genes.

\section{Quantification of relative gene expression by RT-qPCR.}

DNase treatment and first-strand cDNA were conducted with the "Maxima H Minus First Strand cDNA synthesis kit with dsDNase" (Thermo Scientific) using $2 \mu \mathrm{g}$ of total RNA. RT-qPCR assays were conducted following MIQE guidelines (Bustin et al. 2009). Gene-specific primer sets were designed for gene expression analysis with Primer3Plus (Untergasser et al. 2012). RT-qPCR reactions were performed in a LightCycler480 System (Roche) using SYBR Green to monitor cDNA amplifications. Cycling conditions were $5 \mathrm{~min}$ at $95^{\circ} \mathrm{C}$, followed by 45 cycles of $10 \mathrm{~s}$ at $95^{\circ} \mathrm{C}, 5 \mathrm{~s}$ at $58^{\circ} \mathrm{C}$, and $10 \mathrm{~s}$ at $72^{\circ} \mathrm{C}$. For each primer pair and each sample, the PCR efficiency $(\mathrm{E})$ and the quantification cycle $(\mathrm{Cq})$ were assessed using LinRegPCR software version 2014.2 (Ruijter et al. 2009). Amplicon specificity was examined by analysis of the melting curve. Relative gene expression for a gene of interest (GOI) with respect to the reference gene (REF) was calculated using the modified equation $\mathrm{E}_{\mathrm{GOI}}{ }^{\wedge}{ }^{(-\mathrm{CqGOI})} / \mathrm{E}_{\mathrm{REF}}{ }^{\wedge}{ }^{(-\mathrm{CqREF})}$ from Pfaffl (2001). Three independent biological replicates with at least two technical replicates were performed for each sample. Dilution series were made for a number of genes, using genomic DNA to confirm that recorded $\mathrm{Cq}$ values from the experiments were within the linear dynamic range and that efficiencies were consistent with the values calculated using the LinRegPCR program (data not shown). The $\mathrm{Cq}$ value for the reference normalization factor (REF) was calculated by taking the geometric mean of the three $P$. expansum reference genes: the ribosomal 28S RNA (Barad et al. 2012), the 37S ribosomal protein s24 (PEX1_068590), and the histone H3 (PEX1_ 049570) using primer pairs 32/33, 34/35, and 36/37 for the 28SRNA, ribosomal protein s24, and histone H3, respectively. These two latter genes were selected on the basis of the RNASeq data, as their expression paralleled the number of $P$. expansum reads in each sample, and thus, they are good indicators of the amount of fungal RNA at each time point.

\section{Construction and analysis of knockout mutants.}

We selected three genes from the patulin biosynthesis cluster: patK (6-methylsalicylic acid synthase, PEX1_002430), which codes for the first enzyme in the pathway, pat $N$ (isoepoxydon dehydrogenase, PEX1_005160), which catalyzes one of the latest steps, and pat $L$ (transcription factor, PEX1_002400) to construct deletion mutants in order to study the involvement of these genes in the biosynthesis of patulin. For the citrinin biosynthetic cluster, we selected the gene $p k s C T$, which encodes the PKS of the citrinin cluster (PEX1_010400), to construct deletion mutants. Construction of the patK, patL, pat $N$, and pksCT gene replacement plasmids was done as previously described (Marcet-Houben et al. 2012). Basically, flanking regions of the genes, $5^{\prime}$ upstream and 3' downstream of PEXP_094170, PEXP_094140, PEXP_094120, and PEX1_010400, respectively, were PCRamplified from genomic DNA of $P$. expansum PEX1, using specific primer pairs (primers 38 to 53). The cycling protocol consisted of $3 \mathrm{~min}$ at $94^{\circ} \mathrm{C}$ for pre-incubation, then 35 cycles of $30 \mathrm{~s}$ at $94^{\circ} \mathrm{C}$ for denaturation, $45 \mathrm{~s}$ at $58^{\circ} \mathrm{C}$ for annealing, and $1.5 \mathrm{~min}$ at $72^{\circ} \mathrm{C}$ for extension, and a final elongation step of $5 \mathrm{~min}$ at $72^{\circ} \mathrm{C}$. Both DNA fragments, corresponding to promoter and terminator regions, and the digested pRFHU2 vector (Frandsen et al. 2008) were mixed together and were treated with the USER enzyme (New England Biolabs) to obtain plasmids pRFHU2-patK, pRFHU2-patL, pRFHU2-patN, and pRFHU2-pksCT. An aliquot of the mixture was used directly in chemical transformation of Escherichia coli DH5 $\alpha$ cells without prior ligation. Kanamycin-resistant transformants were screened by PCR. Proper fusion was confirmed by DNA sequencing. Then, plasmids were introduced into chemically competent Agrobacterium tumefaciens AGL-1 cells, which were subsequently used to transform $P$. expansum PEX1, as described previously (Buron-Moles et al. 2012). Analysis of 
transformants for gene disruption events was done by PCR. Figures 4A and 5C show schemes of the respective wild-type and gene-disrupted loci. The insertion of the selection marker was checked with primer pair 1/2 (Figs. 4A and 5C). Integration of the T-DNA by homologous recombination was examined with primer pairs $3 / 4$ and 5/6 for pat $K, 9 / 10$ for pat $L$, 13/14 for patN (Fig. 4A), and with 17/4 and 6/18 for pksCT (Fig. 5C). Further testing of deletion of the target gene was done with primer pairs $7 / 8,11 / 12$, and $15 / 16$ for patK, pat $L$, and pat N, respectively (Fig. 4A), and with primers 20/21 for pksCT (Fig. 5C). Real-time genomic PCR analysis was carried out in order to determinate the number of T-DNA copies that had been integrated in the genome of the transformants, following basically the protocol described by Crespo-Sempere and associates (2013), using PEX1 as control. Four primer pairs, 24/25, 26/27, 28/29, and 30/31, were designed within the T-DNA in the promoter regions of the target genes, close to the selection marker. The $P$. expansum $\beta$-tubulin gene (AY674401) (Sanzani et al. 2009) was chosen as reference gene using the primer pair 22/23. All primers were designed using Primer3Plus (Untergasser et al. 2012).

\section{In vitro growth and patulin production.}

Wild type $P$. expansum PEXP, PEX1 and PEX2, as well as pat $K$, pat $L$ and pat $N$ deletion and ectopic mutants were used for the study of fungal growth and patulin production in vitro. Fungal growth and patulin production were determined by centrally inoculating 55-mm PDA plates with a 5- $\mu$ l drop of a $10^{6}$ conidial suspension per milliliter and incubating the plate at $24^{\circ} \mathrm{C}$ in the dark. Colony diameter $(\mathrm{mm})$ and patulin production were recorded for up to 7 days. Patulin was extracted following the protocol described by Sanzani and associates (2012). Basically, patulin was extracted from the mycelium and the medium by washing the petri plates with $3 \mathrm{ml}$ of acidi-

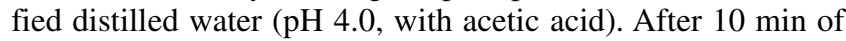
incubation, the washing water was collected and was centrifuged at $10,000 \times g$ for $5 \mathrm{~min}$ at room temperature. Biomass was collected and stored at $-80^{\circ} \mathrm{C}$ until RNA extraction. The supernatant was filtered through a $0.45-\mu \mathrm{m}$ syringe filter and was analyzed by high-performance liquid chromatography (HPLC). Results were expressed as micrograms of patulin per plate. Chromatography was carried out with a Waters HPLC system equipped with a 600 quaternary pump and a 996-photodiode array detector set at $276 \mathrm{~nm}$. Data were analyzed with the Empower software (Waters). Patulin was separated using a Luna C18 reverse column $(250 \times 4.6 \mathrm{~mm}, 5 \mu \mathrm{m}$; Phenomenex $)$ coupled to a $\mu$ Bondapak $\mathrm{C} 18$ guard column $(10 \mu \mathrm{m})$ and using a mobile phase consisting of a mixture of acidic water $(\mathrm{pH} 4.0$, with acetic acid) and acetonitrile (96:4, vol/vol). The flow rate was $1 \mathrm{ml} / \mathrm{min}$ and the injection volume was $20 \mu \mathrm{l}$. Patulin was identified in the samples by comparing the retention time and UV-Vis spectra with those of an authentic standard.

\section{Citrinin analysis.}

To determine citrinin production in $P$. expansum strains, we inoculated $50 \mathrm{ml}$ of PDB with $2 \times 10^{5}$ spores per milliliter. The cultures were incubated in the dark at $28^{\circ} \mathrm{C}$ for 7 days without shaking. The culture supernatant was collected and the biomass was used for RNA extraction. Citrinin concentration was determined directly from the culture supernatant on a Shimadzu prominence HPLC system (Shimadzu corp. Japan) equipped with a degasser (DGU-20A $\mathrm{A}_{3}$ ), two solvent delivery units (LC-20 AD), an auto-sampler (SIL 20 ACHT), and a column oven thermostat operated at $40^{\circ} \mathrm{C}$ (column oven thermostat model CTO-20ASVP). Separation was performed using a Cosmosil column (5C 18 -MS-II), $150 \mathrm{~mm}, 4.6 \mathrm{~mm}$ i. d., $5 \mu \mathrm{m}$ particle size (Nacalai USA, Inc.). The mobile phase was $70 \%$ methanol and acetonitrile and $30 \%$ water with $0.1 \%$ acetic acid and $0.1 \%$ ammonium acetate at a flow rate of $0.8 \mathrm{ml} / \mathrm{min}$. The sample volume injected was $20 \mu \mathrm{l}$ and the minimum concentration calibrate was 2 parts per billion. The HPLC system was coupled to a 3200 TRAP LC/MS/MS mass spectrometer (Applied Biosystems, MDS Sciex) with an electrospray Turbo V ionization source. Acquisition was performed in the multiple reaction monitoring mode (MRM). Source conditions were established as follows: ion spray voltage (IS), $-4.5 \mathrm{kV}\left(\mathrm{ESI}^{-}\right)$; collision gas medium and curtain gas, $10 \mathrm{kPa}$ (CUR); ion source gas 1 (GS 1, nebulizer gas) and 2 (GS 2, turbo gas), 50 and $60 \mathrm{kPa}$, respectively; ion source temperature, $350^{\circ} \mathrm{C}$ (TEMP). High purity nitrogen $(>98 \%)$ was produced by NitroGen 3G (Peak Scientific) and was used as desolvation, nebulization, and collision gas. Tandem mass spectrometry parameter optimization was obtained by direct infusion at $10 \mu \mathrm{l} / \mathrm{min}$ of a $100 \mathrm{ng} / \mathrm{ml}$ citrinin standard solution in $50 \%$ methanol aqueous solution. Declustering potential $(-60 \mathrm{~V})$, collision energy $(-9.5 \mathrm{~V})$, and cell exit potential $(-4 \mathrm{~V})$ voltages were established for each MRM transition. All data were acquired and processed using Analyst 1.5.1 software.

\section{ACKNOWLEDGMENTS}

The technical assistance of A. Izquierdo (IATA-CSIC, Valencia, Spain) is gratefully acknowledged. We are grateful to $\mathrm{H}$. Himmelbauer and the CRG sequencing core facility for their technical assistance. Work at L. González-Candelas' lab was partially supported by the Spanish Ministry of Economy and Innovation (Research Grants AGL-2008-04828-C03-02 and AGL2011-30519-C03-01) and by the Generalitat Valenciana, Spain (PROMETEO/2010/010 and PROMETEOII/2014/027). A.-R. Ballester is grateful to CSIC and the European Social Fund for her postdoctoral contract JAE-Doc. C. Selma-Lázaro is recipient of a FPI Predoctoral fellowship from the Spanish MICINN (BES-2012-054595). The T. Gabaldón group research is funded, in part, by a grant from the Spanish ministry of Economy and Competitiveness (BIO2012-37161), a Grant from the Qatar National Research Fund grant (NPRP 5-298-3-086), and a grant from the European Research Council under the European Union's Seventh Framework Programme (FP/2007-2013)/ERC (Grant Agreement n. ERC-2012StG-310325). The funders had no role in study design, data collection and analysis, decision to publish, or preparation of the manuscript.

\section{LITERATURE CITED}

Al-Samarrai, T., and Schmid, J. 2000. A simple method for extraction of fungal genomic DNA. Lett. Appl. Microbiol. 30:53-56.

Andersen, B., Smedsgaard, J., and Frisvad, J. C. 2004. Penicillium expansum: Consistent production of patulin, chaetoglobosins, and other secondary metabolites in culture and their natural occurrence in fruit products. J. Agric. Food Chem. 52:2421-2428.

Artigot, M. P., Loiseau, N., Laffitte, J., Mas-Reguieg, L., Tadrist, S., Oswald, I. P., and Puel, O. 2009. Molecular cloning and functional characterization of two CYP619 cytochrome P450s involved in biosynthesis of patulin in Aspergillus clavatus. Microbiology 155:1738-1747.

Barad, S., Horowitz, S. B., Moskovitch, O., Lichter, A., Sherman, A., and Prusky, D. 2012. A Penicillium expansum glucose oxidase-encoding gene, $G O X 2$, is essential for gluconic acid production and acidification during colonization of deciduous fruit. Mol. Plant-Microbe Interact. 25:779-788.

Barad, S., Horowitz, S., Kobiler, I., Sherman, A., and Prusky, D. B. 2014 Accumulation of the mycotoxin patulin in the presence of gluconic acid contributes to pathogenicity of Penicillium expansum. Mol. PlantMicrobe Interact. 27:66-77.

Birney, E., Clamp, M., and Durbin, R. 2004. GeneWise and Genomewise. Genome Res. 14:988-995.

Blanc, P., Laussac, J., Le Bars, J., Le Bars, P., Loret, M., Pareilleux, A., Prome, D., Prome, J., Santerre, A., and Goma, G. 1995. Characterization of monascidin A from Monascus as citrinin. Int. J. Food Microbiol. 27:201-213.

Buron-Moles, G., López-Pérez, M., González-Candelas, L., Viñas, I., Teixidó, N., Usall, J., and Torres, R. 2012. Use of GFP-tagged strains of Penicillium digitatum and Penicillium expansum to study host-pathogen interactions in oranges and apples. Int. J. Food Microbiol. 160:162170. 
Bustin, S. A., Benes, V., Garson, J. A., Hellemans, J., Huggett, J., Kubista, M., Mueller, R., Nolan, T., Pfaffl, M. W., Shipley, G. L., Vandesompele, J., and Wittwer, C. T. 2009. The MIQE guidelines: Minimum information for publication of quantitative real-time PCR experiments. Clin. Chem. 55:611-622.

Capella-Gutierrez, S., Silla-Martinez, J. M., Gabaldon, T. 2009. trimAl: A tool for automated alignment trimming in large-scale phylogenetic analyses. Bioinformatics 25:1972-1973.

Cappellini, R., Ceponis, M., and Lightner, G. 1987. Disorders in apple and pear shipments to the New York market, 1972-1984. Plant Dis.71:852856

Condon, B. J., Leng, Y., Wu, D., Bushley, K. E., Ohm, R. A., Otillar, R., Martin, J., Schackwitz, W., Grimwood, J., MohdZainudin, N., Xue, C., Wang, R., Manning, V. A., Dhillon, B., Tu, Z. J., Steffenson, B. J., Salamov, A., Sun, H., Lowry, S., LaButti, K., Han, J., Copeland, A., Lindquist, E., Barry, K., Schmutz, J., Baker, S. E., Ciuffetti, L. M., Grigoriev, I. V., Zhong, S., and Turgeon, B. G. 2013. Comparative genome structure, secondary metabolite, and effector coding capacity across Cochliobolus pathogens. PLoS Genet. 9:e1003233. Published online.

Conesa, A., Götz, S., García-Gómez, J. M., Terol, J., Talón, M., and Robles, M. 2005. Blast2GO: A universal tool for annotation, visualization and analysis in functional genomics research. Bioinformatics 21:3674-3676.

Crespo-Sempere, A., Selma-Lázaro, C., Martínez-Culebras, P., and González-Candelas, L. 2013. Characterization and disruption of the cipC gene in the ochratoxigenic fungus Aspergillus carbonarius. Food Res. Int. 54:697-705

Cheeseman, K., Ropars, J., Renault, P., Dupont, J., Gouzy, J., Branca, A., Abraham, A.-L., Ceppi, M., Conseiller, E., Debuchy, R., Malagnac, F., Goarin, A., Silar, P., Lacoste, S., Sallet, E., Bensimon, A., Giraud, T., and Brygoo, Y. 2014. Multiple recent horizontal transfers of a large genomic region in cheese making fungi. Nat. Commun. 5.

de Jonge, R., Bolton, M. D., and Thomma, B. P. 2011. How filamentous pathogens co-opt plants: The ins and outs of fungal effectors. Curr. Opin. Plant Biol. 14:400-406.

Donofrio, N. M., and Raman, V. 2012. Roles and delivery mechanisms of fungal effectors during infection development: Common threads and new directions. Curr. Opin. Microbiol. 15:692-698.

Edgar, R. C. 2004. MUSCLE: A multiple sequence alignment method with reduced time and space complexity. BMC Bioinformatics 5:113.

Fitzpatrick, D. A. 2012. Horizontal gene transfer in fungi. FEMS (Fed. Eur. Microbiol. Soc.) Microbiol. Lett. 329:1-8.

Frandsen, R. J., Andersson, J. A., Kristensen, M. B., and Giese, H. 2008 Efficient four fragment cloning for the construction of vectors for targeted gene replacement in filamentous fungi. BMC Mol. Biol. 9:70.

Frisvad, J. C., and Filtenborg, O. 1983. Classification of terverticillate penicillia based on profiles of mycotoxins and other secondary metabolites. Appl. Environ. Microbiol. 46:1301-1310.

Frisvad, J. C., and Samson, R. A. 2004. Polyphasic taxonomy of Penicillium subgenus Penicillium: A guide to identification of food and airborne terverticillate Penicillia and their mycotoxins. Stud. Mycol. 49:1174

Gabaldón, T. 2008. Large-scale assignment of orthology: Back to phylogenetics. Genome Biol 9:235.

Guindon, S., Dufayard, J.-F., Lefort, V., Anisimova, M., Hordijk, W., and Gascuel, O. 2010. New algorithms and methods to estimate maximumlikelihood phylogenies: Assessing the performance of PhyML 3.0. Syst. Biol. 59:307-321.

Guyon, K., Balague, C., Roby, D., and Raffaele, S. 2014. Secretome analysis reveals effector candidates associated with broad host range necrotrophy in the fungal plant pathogen Sclerotinia sclerotiorum. BMC Genomics 15:336.

Hadas, Y., Goldberg, O., Pines, O., and Prusky, D. 2007. Involvement of gluconic acid and glucose oxidase in the pathogenicity of Penicillium expansum in apples. Phytopathology 97:384-390.

Hopkins, J. 1993. The toxicological hazards of patulin. Food Chem. Toxicol. 31:455

Huerta Cepas, J., and Gabaldón, T. 2011. Assigning duplication events to relative temporal scales in genome-wide studies. Comput. Appl. Biosci. $27 \cdot 38-45$

Huerta-Cepas, J., Dopazo, J., and Gabaldón, T. 2010. ETE: A python environment for tree exploration. BMC Bioinformatics 11:24.

Huerta-Cepas, J., Capella-Gutiérrez, S., Pryszcz, L. P., Marcet-Houben, M., and Gabaldón, T. 2014. PhylomeDB v4: Zooming into the plurality of evolutionary histories of a genome. Nucleic Acids Res. 42:D897-902.

Janisiewicz, W. J., Usall, J., and Bors, B. 1992. Nutritional enhancement of biocontrol of blue mold on apples. Phytopathology 82:1364-1370

Jurick, W. M., Janisiewicz, W. J., Saftner, R. A., Vico, I., Gaskins, V. L., Park, E., Forsline, P. L., Fazio, G., and Conway, W. S. 2011. Identification of wild apple germplasm (Malus spp.) accessions with resistance to the postharvest decay pathogens Penicillium expansum and Colletotrichum acutatum. Plant Breeding 130:481-486.

Kal, A. J., van Zonneveld, A. J., Benes, V., van den Berg, M., Koerkamp, M. G., Albermann, K., Strack, N., Ruijter, J. M., Richter, A., Dujon, B., Ansorge, W., and Tabak, H. F. 1999. Dynamics of gene expression revealed by comparison of serial analysis of gene expression transcript profiles from yeast grown on two different carbon sources. Mol. Biol. Cell 10:1859-1872

Katoh, K., Kuma, K.-i., Toh, H., and Miyata, T. 2005. MAFFT version 5: Improvement in accuracy of multiple sequence alignment. Nucleic Acids Res. 33:511-518.

Khaldi, N., Seifuddin, F. T., Turner, G., Haft, D., Nierman, W. C., Wolfe, K. H., and Fedorova, N. D. 2010. SMURF: Genomic mapping of fungal secondary metabolite clusters. Fungal Genet. Biol. 47:736-741.

Kombrink, A., and Thomma, B. P. H. J. 2013. LysM effectors: Secreted proteins supporting fungal life. PLoS Path. 9:e1003769. Published online.

Lassmann, T., and Sonnhammer, E. L. 2005. Kalign-an accurate and fast multiple sequence alignment algorithm. BMC Bioinformatics 6:298

Leistner, L., and Pitt, J. 1977. Miscellaneous Penicillium toxins. Pages 639-653 in:Mycotoxins in Human and Animal Health. Pathotox Publishers, Park Forest South, IL, U.S.A.

Li, H., and Durbin, R. 2009. Fast and accurate short read alignment with Burrows-Wheeler transform. Bioinformatics 25:1754-1760.

Li, Y.-P., Xu, Y., and Huang, Z.-B. 2012. Isolation and characterization of the citrinin biosynthetic gene cluster from Monascus aurantiacus. Biotechnol. Lett. 34:131-136.

Liu, G., Zhang, L., Wei, X., Zou, G., Qin, Y., Ma, L., Li, J., Zheng, H. Wang, S., and Wang, C. 2013. Genomic and secretomic analyses reveal unique features of the lignocellulolytic enzyme system of Penicillium decumbens. PloS one 8:e55185. Published online.

Lombard, V., Golaconda Ramulu, H., Drula, E., Coutinho, P. M., and Henrissat, B. 2014. The carbohydrate-active enzymes database (CAZy) in 2013. Nucleic Acids Res. 42:D490-D495.

López-Pérez, M., Ballester, A.-R., and González-Candelas, L. 2014. Identification and functional analysis of Penicillium digitatum genes putatively involved in virulence towards citrus fruit. Mol. Plant Pathol. doi: 10.1111/mpp.12179. Published online.

Luo, R., Liu, B., Xie, Y., Li, Z., Huang, W., Yuan, J., He, G., Chen, Y., Pan, Q., and Liu, Y. 2012. SOAPdenovo2: An empirically improved memory-efficient short-read de novo assembler. Gigascience 1:18.

Marcet-Houben, M., and Gabaldón, T. 2010. Acquisition of prokaryotic genes by fungal genomes. Trends Genet. 26:5-8.

Marcet-Houben, M., Ballester, A.-R., De la Fuente, B., Harries, E., Marcos, J. F., González-Candelas, L., and Gabaldón, T. 2012. Genome sequence of the necrotrophic fungus Penicillium digitatum, the main postharvest pathogen of citrus. BMC Genomics 13:646.

Martins, M. L., Gimeno, A., Martins, H. M., and Bernardo, F. 2002. Cooccurrence of patulin and citrinin in Portuguese apples with rotten spots. Food Addit. Contam. 19:568-574.

McCallum, J., Tsao, R., and Zhou, T. 2002. Factors affecting patulin production by Penicillium expansum. J. Food Prot. 65:1937-1942.

McKenna, A., Hanna, M., Banks, E., Sivachenko, A., Cibulskis, K., Kernytsky, A., Garimella, K., Altshuler, D., Gabriel, S., and Daly, M. 2010. The Genome Analysis Toolkit: A MapReduce framework for analyzing next-generation DNA sequencing data. Genome Res. 20:12971303.

Moriya, Y., Itoh, M., Okuda, S., Yoshizawa, A. C., and Kanehisa, M. 2007. KAAS: An automatic genome annotation and pathway reconstruction server. Nucleic Acids Res. 35:W182-W185.

Mortazavi, A., Williams, B. A., McCue, K., Schaeffer, L., and Wold, B. 2008. Mapping and quantifying mammalian transcriptomes by RNASeq. Nat. Methods 5:621-628.

Neri, F., Donati, I., Veronesi, F., Mazzoni, D., and Mari, M. 2010. Evaluation of Penicillium expansum isolates for aggressiveness, growth and patulin accumulation in usual and less common fruit hosts. Int. J. Food Microbiol. 143:109-117.

Park, B. H., Karpinets, T. V., Syed, M. H., Leuze, M. R., and Uberbacher, E. C. 2010. CAZymes Analysis Toolkit (CAT): Web service for searching and analyzing carbohydrate-active enzymes in a newly sequenced organism using CAZy database. Glycobiology 20:1574-1584.

Paterson, R. R. M., Venâncio, A., and Lima, N. 2004. Solutions to Penicillium taxonomy crucial to mycotoxin research and health. Res. Microbiol. 155:507-513.

Pfaffl, M. W. 2001. A new mathematical model for relative quantification in real-time RT-PCR. Nucleic Acids Res. 29:e45.

Pitt, J. I., and Hocking, A. D. 2009. Penicillium and related genera. Pages 169-273 in: Fungi and Food Spoilage, Springer U.S.A., New York.

Prusky, D., McEvoy, J. L., Saftner, R., Conway, W. S., and Jones, R. 2004. Relationship between host acidification and virulence of Penicillium 
spp. on apple and citrus fruit. Phytopathology 94:44-51.

Qin, G., Tian, S., Chan, Z., and Li, B. 2007. Crucial role of antioxidant proteins and hydrolytic enzymes in pathogenicity of Penicillium expansum: Analysis based on proteomic approach. Mol. Cell. Proteomics 6:425-438.

Rasmussen, T. B., and Givskov, M. 2006. Quorum sensing inhibitors: A bargain of effects. Microbiology 152:895-904.

Rodrigues, M. L., Franzen, A. J., Nimrichter, L., and Miranda, K. 2013. Vesicular mechanisms of traffic of fungal molecules to the extracellular space. Curr. Opin. Microbiol. 16:414-420.

Rosenberger, D. A. 1997. Recent research and changing options for controlling postharvest decays of apples. In Proc. Harvesting, Handling, and Storage Workshop. Northeast Reg. Agric. Eng. Serv. Publ. NRAES112. Cornell University, Ithaca, NY, U.S.A.

Ruijter, J. M., Ramakers, C., Hoogaars, W. M. H., Karlen, Y., Bakker, O., van den Hoff, M. J. B., and Moorman, A. F. M. 2009. Amplification efficiency: Linking baseline and bias in the analysis of quantitative PCR data. Nucleic Acids Res. 37:e45.

Sánchez-Torres, P., and González-Candelas, L. 2003. Isolation and characterization of genes differentially expressed during the interaction between apple fruit and Penicillium expansum. Mol. Plant Pathol. 4:447-457.

Sanzani, S. M., Schena, L., Nigro, F., de Girolamo, A., and Ippolito, A 2009. Effect of quercetin and umbelliferone on the transcript level of Penicillium expansum genes involved in patulin biosynthesis. Eur. J. Plant Pathol. 125:223-233.

Sanzani, S. M., Reverberi, M., Punelli, M., Ippolito, A., and Fanelli, C. 2012. Study on the role of patulin on pathogenicity and virulence of Penicillium expansum. Int. J. Food Microbiol. 153:323-331.

Schümann, J., and Hertweck, C. 2007. Molecular basis of cytochalasan biosynthesis in fungi: Gene cluster analysis and evidence for the in volvement of a PKS-NRPS hybrid synthase by RNA silencing. J. Am. Chem. Soc. 129:9564-9565.

Sharma, R. P. 1993. Immunotoxicity of mycotoxins. J. Dairy Sci. 76:892 897.

Shimizu, T., Kinoshita, H., Ishihara, S., Sakai, K., Nagai, S., and Nihira, T. 2005. Polyketide synthase gene responsible for citrinin biosynthesis in Monascus purpureus. Appl. Environ. Microbiol. 71:3453-3457.

Sommer, N. F., Buchanan, J. R., and Fortlage, R. J. 1974. Production of patulin by Penicillium expansum. Applied Microbiol. 28:589-593.

Stamatakis, A., Aberer, A. J., Goll, C., Smith, S. A., Berger, S. A., and Izquierdo-Carrasco, F. 2012. RAxML-Light: A tool for computing terabyte phylogenies. Bioinformatics 28:2064-2066.

Stanke, M., Schöffmann, O., Morgenstern, B., and Waack, S. 2006. Gene prediction in eukaryotes with a generalized hidden Markov model that uses hints from external sources. BMC Bioinformatics 7:62.

Subramani, R., Kumar, R., Prasad, P., and Aalbersberg, W. 2013. Cytotoxic and antibacterial substances against multi-drug resistant pathogens from marine sponge symbiont: Citrinin, a secondary metabolite of Penicillium sp. Asian Pac. J. Trop. Biomed. 3:291-296.

Teixidó, N., Viñas, I., Usall, J., and Magan, N. 1998. Control of blue mold of apples by preharvest application of Candida sake grown in media with different water activity. Phytopathology 88:960-964.

Tian, S., Qin, G., and Li, B. 2013. Reactive oxygen species involved in regulating fruit senescence and fungal pathogenicity. Plant Mol. Biol. Rep. 82:593-602.

The UniProt Consortium, U. 2014. Activities at the Universal Protein Resource (UniProt). Nucleic Acids Res. 42:D191-D198.

Untergasser, A., Cutcutache, I., Koressaar, T., Ye, J., Faircloth, B. C., Remm, M., and Rozen, S. G. 2012. Primer3-New capabilities and interfaces. Nucleic Acids Res. 40:e115.

van den Berg, M. A., Albang, R., Albermann, K., Badger, J. H., Daran, J.-
M., M Driessen, A. J., Garcia-Estrada, C., Fedorova, N. D., Harris, D. M., Heijne, W. H. M., Joardar, V., W Kiel, J. A. K., Kovalchuk, A., Martin, J. F., Nierman, W. C., Nijland, J. G., Pronk, J. T., Roubos, J. A., van der Klei, I. J., van Peij, N. N. M. E., Veenhuis, M., von Dohren, H., Wagner, C., Wortman, J., and Bovenberg, R. A. L. 2008. Genome sequencing and analysis of the filamentous fungus Penicillium chrysogenum. Nat. Biotechnol. 26:1161-1168.

Velasco, R., Zharkikh, A., Affourtit, J., Dhingra, A., Cestaro, A. Kalyanaraman, A., Fontana, P., Bhatnagar, S. K., Troggio, M., Pruss, D., Salvi, S., Pindo, M., Baldi, P., Castelletti, S., Cavaiuolo, M., Coppola, G., Costa, F., Cova, V., Dal Ri, A., Goremykin, V., Komjanc, M., Longhi, S., Magnago, P., Malacarne, G., Malnoy, M., Micheletti, D., Moretto, M., Perazzolli, M., Si-Ammour, A., Vezzulli, S., Zini, E., Eldredge, G., Fitzgerald, L. M., Gutin, N., Lanchbury, J., Macalma, T., Mitchell, J. T., Reid, J., Wardell, B., Kodira, C., Chen, Z., Desany, B., Niazi, F., Palmer, M., Koepke, T., Jiwan, D., Schaeffer, S., Krishnan, V., Wu, C., Chu, V. T., King, S. T., Vick, J., Tao, Q., Mraz, A., Stormo, A., Stormo, K., Bogden, R., Ederle, D., Stella, A., Vecchietti, A., Kater, M. M., Masiero, S., Lasserre, P., Lespinasse, Y., Allan, A. C., Bus, V., Chagne, D., Crowhurst, R. N., Gleave, A. P., Lavezzo, E., Fawcett, J. A., Proost, S., Rouze, P., Sterck, L., Toppo, S., Lazzari, B., Hellens, R. P., Durel, C.E., Gutin, A., Bumgarner, R. E., Gardiner, S. E., Skolnick, M., Egholm, M., Van de Peer, Y., Salamini, F., and Viola, R. 2010. The genome of the domesticated apple (Malus x domestica Borkh.). Nat. Genet. 42:833839.

Vilanova, L., Viñas, I., Torres, R., Usall, J., Buron-Moles, G., and Teixidó, N. 2014a. Acidification of apple and orange hosts by Penicillium digitatum and Penicillium expansum. Int. J. Food Microbiol. 178:39-49.

Vilanova, L., Wisniewski, M., Norelli, J., Viñas, I., Torres, R., Usall, J., Phillips, J., Droby, S., and Teixidó, N. 2014b. Transcriptomic profiling of apple in response to inoculation with a pathogen (Penicillium expansum) and a non-pathogen (Penicillium digitatum). Plant Mol. Biol. Rep. 32:566-583.

Vleeshouwers, V. G. A. A., and Oliver, R. P. 2014. Effectors as tools in disease resistance breeding against biotrophic, hemibiotrophic, and necrotrophic plant pathogens. Mol. Plant-Microbe Interact. 27:196-206.

Wallace, I. M., O'Sullivan, O., Higgins, D. G., and Notredame, C. 2006 M-Coffee: Combining multiple sequence alignment methods with TCoffee. Nucleic Acids Res. 34:1692-1699.

White, S., O'Callaghan, J., and Dobson, A. D. W. 2006. Cloning and molecular characterization of Penicillium expansum genes upregulated under conditions permissive for patulin biosynthesis. FEMS (Fed. Eur. Microbiol. Soc.) Microbiol. Lett. 255:17-26.

Wouters, M. F. A., and Speijers, G. J. A. 1996. Patulin Food Additives Series 35 Toxicological Evaluation of Certain Food Additives and Contaminants, vol. 35. World Health Organization, Geneva:377-340.

Wu, S., Zhu, Z., Fu, L., Niu, B., and Li, W. 2011. WebMGA: A customizable web server for fast metagenomic sequence analysis. BMC Genomics $12: 444$

Yang, Y., Zhao, H., Barrero, R., Zhang, B., Sun, G., Wilson, I., Xie, F., Walker, K., Parks, J., Bruce, R., Guo, G., Chen, L., Zhang, Y., Huang, X., Tang, Q., Liu, H., Bellgard, M., Hoffman, A., Lai, J., and Qiu, D. 2014. Genome sequencing and analysis of the paclitaxel-producing endophytic fungus Penicillium aurantiogriseum NRRL 62431. BMC Genomics 15:69.

Yin, Y., Mao, X., Yang, J., Chen, X., Mao, F., and Xu, Y. 2012. dbCAN: A web resource for automated carbohydrate-active enzyme annotation. Nucleic Acids Res. 40:W445-W451.

Zhang, C.-L., Zheng, B.-Q., Lao, J.-P., Mao, L.-J., Chen, S.-Y., Kubicek, C. P., and Lin, F.-C. 2008. Clavatol and patulin formation as the antagonistic principle of Aspergillus clavatonanicus, an endophytic fungus of Taxus mairei. Appl. Microbiol. Biotechnol. 78:833-840. 